\title{
APP as a Protective Factor in Acute Neuronal Insults
}

\author{
Dimitri Hefter ${ }^{1,2}$ and Andreas Draguhn ${ }^{1 *}$ \\ ${ }^{1}$ Institute of Physiology and Pathophysiology, Heidelberg University, Heidelberg, Germany, ${ }^{2}$ Department of Psychiatry and \\ Psychotherapy, Central Institute of Mental Health, Medical Faculty Mannheim, Heidelberg University, Mannheim, Germany
}

Despite its key role in the molecular pathology of Alzheimer's disease (AD), the physiological function of amyloid precursor protein (APP) is unknown. Increasing evidence, however, points towards a neuroprotective role of this membrane protein in situations of metabolic stress. A key observation is the up-regulation of APP following acute (stroke, cardiac arrest) or chronic (cerebrovascular disease) hypoxic-ischemic conditions. While this mechanism may increase the risk or severity of AD, APP by itself or its soluble extracellular fragment APPs $\alpha$ can promote neuronal survival. Indeed, different animal models of acute hypoxia-ischemia, traumatic brain injury (TBI) and excitotoxicity have revealed protective effects of APP or APPs $\alpha$. The underlying mechanisms involve APP-mediated regulation of calcium homeostasis via NMDA receptors (NMDAR), voltage-gated calcium channels (VGCC) or internal calcium stores. In addition, APP affects the expression of survival- or apoptosis-related genes as well as neurotrophic factors. In this review, we summarize the current understanding of the neuroprotective role of APP and APPs $\alpha$ and possible implications for future research and new therapeutic

\section{OPEN ACCESS}

Edited by:

Thomas Deller,

Goethe-University, Germany

Reviewed by:

Dirk Isbrandt,

DZNE Bonn \& University of Cologne,

Germany

Wickliffe C. Abraham,

University of Otago, New Zealand Maximilian Lenz,

University of Düsseldorf, Germany

*Correspondence: Andreas Draguhn andreas.draguhn@physiologie. uniheidelberg.de

Received: 07 November 2016 Accepted: 16 January 2017 Published: 02 February 2017

Citation: Hefter D and Draguhn A (2017) APP as a Protective Factor in Acute Neuronal Insults. Front. Mol. Neurosci. 10:22. doi: 10.3389/fnmol.2017.00022 strategies.

Keywords: Alzheimer, ischemia, calcium toxicity, cell death, amyloid precursor protein, stroke, traumatic brain injury, neuroprotection

\section{INTRODUCTION}

Amyloid precursor protein (APP) has been first described in 1987 as a potential substrate of pathological deposits in the nervous system (Kang et al., 1987). By now, there is good evidence from multiple lines of research that specific domains of APP do indeed contribute to amyloid plaques as found in patients with Alzheimer's disease (AD; Hardy and Selkoe, 2002). On the other hand, the function of this ubiquitously expressed protein in healthy brains remains poorly understood. Recent evidence from neurological patients and from different disease models hint towards a potential neuroprotective function of APP under conditions of acute cellular insult: APP is up-regulated following hypoxia, ischemia or traumatic brain injury (TBI; Van den Heuvel et al., 1999; Pottier et al., 2012). This reaction coincides well with some known interactions between APP and other proteins which are relevant for homeostatic regulation of cell integrity under stressful conditions, such as certain glutamate receptors, calcium channels or gene-regulatory networks (Russo et al., 2005). With respect to the underlying molecular mechanisms it is important to note that the integral membrane protein APP can give rise to both, protective and potentially damaging molecules following cleavage by different secretases (Brunholz et al., 2012). These cleavage processes keep a balance between different amyloidogenic and non-amyloidogenic products of APP, including the protective APPs $\alpha$ fragment which is secreted into the extracellular space (Mattson et al., 1993a). Together, APP or its fragments may well have a neuroprotective role during acute challenges of 
neuronal integrity, and it may exert this function by regulating neuronal calcium homeostasis and cell survival. Novel findings on APP-related neuroprotective mechanisms open promising new therapeutic strategies in stroke, $\mathrm{AD}$ and TBI.

In the present review article, we summarize the evidence for a neuroprotective function of APP in the adult brain. After a brief introduction of the protein and its metabolites, we summarize current knowledge from clinical, animal and in vitro studies about its role in stroke, brain injury and neurodegeneration. Finally, we discuss possible mechanisms and point out several promising therapeutic targets.

\section{APP STRUCTURE, EXPRESSION, TRAFFICKING, CLEAVAGE AND SUBCELLULAR LOCALIZATION}

APP is a type- 1 transmembrane protein comprising a long extracellular N-terminal domain, a transmembrane region and an intracellular C-terminal domain, APP intracellular domain (AICD; Kang et al., 1987). Alternative splicing of the APP gene, which is located on chromosome 21, produces three isoforms containing 695, 751 and 770 amino acids, respectively (Beyreuther et al., 1993). While APP751 and APP770 are expressed almost ubiquitously, APP695 can be found nearly exclusively in neurons. Depending on the isoform, the APP extracellular domain consists of up to six different subdomains with specific structural motives and various binding partners such as extracellular matrix proteins (heparine, collagene, laminine, proteoglycans), metals (copper, zinc) and regulatory proteins (LDL-receptor-related protein, F-spondin; Gralle and Ferreira, 2007; Müller and Zheng, 2012). After translation in the endoplasmic reticulum (ER), APP undergoes various post-translational modifications in the Golgi complex before it is transported to the cell membrane (Caporaso et al., 1994). The mature membrane protein can be processed by different membrane-associated proteolytic enzymes, beginning with cleavage of the transmembrane domain by $\gamma$-secretase. Subsequent cleavage by $\alpha$-secretase results in three fragments: AICD, a short p3 fragment and the secreted soluble APP $\alpha$ (APPs $\alpha$ ). Alternatively, cleavage by the $\beta$-secretase BACE- 1 (Beta-site APP Cleaving Enzyme 1) releases APPs $\beta$ and the neurotoxic amyloid $\beta(A \beta)$ peptide (refer to Haass et al., 2012 for review on processing of APP). Under normal conditions, only a small fraction of the expressed APP is secreted, and cleavage by $\alpha$-secretases outweighs the amyloidogenic pathway by far (Hick et al., 2015).

In neurons, APP is found in somatodendritic and axonal compartments as well as in the presynaptic active zone (Laßek et al., 2016) which it reaches by fast axonal transport (Brunholz et al., 2012). Its intracellular trafficking involves four different neuronal trafficking adaptors including Mint1 and is regulated by tyrosine phosphorylation (Dunning et al., 2016). Expression, trafficking and processing of APP are complexly regulated, including prominent changes during pathological states. APP expression is upregulated under conditions of metabolic stress (Hoyer et al., 2005), ischemia (Pottier et al., 2012), brain injury
(Van den Heuvel et al., 1999) and inflammation (HerbstRobinson et al., 2015). APP processing and degradation differ under conditions of acute stress. In response to increased levels of intracellular calcium, APP is degraded via the ubiquitinproteasome proteolytic pathway (Jung et al., 2015). Facilitated degradation might counteract overexpression of APP under conditions of acute stress, prevent accumulation of misfolded protein and its processing into $\mathrm{A} ß$. As an additional adaptive mechanism, cleavage of the protein is regulated by synaptic activity, affecting the balance between amyloidogenic and non-amyloidogenic pathways (Kamenetz et al., 2003; Cirrito et al., 2005). Intriguingly, APP is expressed and cleaved heterogeneously in different types of neurons and in astrocytes and in different brain areas, which might contribute to variable susceptibility to insults between brain regions and cell types (Del Turco et al., 2016; Liao et al., 2016). Activated by proinflammatory cytokines, astrocytes were shown both to contribute to $A ß$ production as well as to stimulate the secretion of $\mathrm{APP} \alpha \alpha$, suggesting a significant contribution of glia cells to production and cleavage of APP and a tight coupling between APP processing and the immune system (Zhao et al., 2011; Yang et al., 2015). While still quite superficially understood, this activity- and stress-dependent multi-level relation of APP in neural, glial and immune cell response strongly suggests a role as an acute phase protein with functions in cellular survival under metabolically challenging conditions.

\section{FUNCTIONS OF APP AND ITS METABOLITES}

APP is highly conserved across different phyla including mammals, insects and nematodes, suggesting that the protein has advantageous effects on survival and reproduction of animals (Müller and Zheng, 2012; van der Kant and Goldstein, 2015). Indeed, in the nematode C. elegans knock-out of APP-like protein (APL-1) is lethal (Hornsten et al., 2007). Drosophila lacking the APP ortholog APPL exhibit severe memory deficits (Bourdet et al., 2015). Most knowledge on systemic functions of APP has been gained from studies of genetically modified rodents. Remarkably, mice lacking APP are viable, fertile, and exhibit a relatively mild phenotype. Alterations include reduced body and brain weight and several neurological symptoms like reduced grip strength (Weyer et al., 2011; Caldwell et al., 2013), deficits in spatial memory (Puzzo et al., 2011), and increased susceptibility to seizures (Steinbach et al., 1998). This phenotype may be related to changes at the cellular and network level like reduced numbers of dendritic spines, reduced hippocampal LTP and altered short-term plasticity (Seabrook et al., 1999; Weyer et al., 2011; Jedlicka et al., 2012; Korte et al., 2012). The absence of more severe deficits is likely due to the existence of homologous proteins, called APLP1 and APLP2, which can compensate the lack of APP due to overlapping functions (Aydin et al., 2012). Indeed, double knockout mice lacking two of the three homologous proteins are much more heavily affected: mice lacking APP and the globally expressed APLP2 as well as APLP1-KO/APLP2-KO mice die perinatally 
due to impaired neuromuscular transmission (Wang et al., 2005), while mice deficient for APP and APLP1, which is predominantly expressed in the brain, survive birth but exhibit rather severe deficits (Heber et al., 2000). Triple knock-out mice die during embryonic development or shortly after birth and show lissencephaly-like cortical malformations (Herms et al., 2004), pointing towards a role for APP and its homologs in essential developmental mechanisms like neuronal migration, neurite outgrowth and synaptogenesis. Detailed studies at the cellular and molecular level revealed several further functions of APP. The protein is involved in regulation of synaptic vesicle exocytosis (Kohli et al., 2012) glutamatergic, GABAergic and cholinergic synaptic transmission (Wang et al., 2005, 2014; Schrenk-Siemens et al., 2008) and synapse formation (Priller et al., 2006). Interestingly, it also regulates endosomal phosphoinositide metabolism and prevents neurodegeneration (Balklava et al., 2015), and it interacts with a large variety of survival-related cascades (Russo et al., 2005; Venezia et al., 2007).

\section{APPs $\alpha$ and APPs $\beta$}

Several functions of APP seem to be mediated by its soluble cleavage product APPs $\alpha$. Selective expression of APPs $\alpha$ in mice with $\mathrm{APP}^{-/-}$background abolishes most of their deficits, rescuing LTP as well as the typical anatomical and behavioral abnormalities (Ring et al., 2007; Hick et al., 2015). Mice selectively expressing APPs $\alpha$ on APP-KO/APLP2$\mathrm{KO}$ background (which by itself is lethal) survive well into adulthood and show only a mildly altered phenotype, similar to simple APP-KO animals (Zhang et al., 2013). Enhancing APPs $\alpha$ levels by over-expression of ADAM-10 increases cortical synaptogenesis in vivo (Bell et al., 2008). Intraventricular application of APPs $\alpha$ enhances memory in mice (Meziane et al., 1998). Altogether, there is strong evidence that APPs $\alpha$ mediates many of the effects of APP on brain development and supports several cognitive functions. In addition, the APPs $\alpha$ fragment has been shown to mediate a variety of neuroprotective and trophic effects (Hick et al., 2015; Fol et al., 2016; Hefter et al., 2016; Plummer et al., 2016), as discussed in following sections. It is important to note that secretion of APPs $\alpha$ is regulated by neuronal activity (Kirazov et al., 1997; Gakhar-Koppole et al., 2008) and by activated astrocytes (Yang et al., 2015). This may point towards state-dependent functions of the protein, in line with the neuroprotective effects described below. The trophic effects of APPs $\alpha$ are dosedependent, beginning as low as $100 \mathrm{pM}$, reaching an optimum at $10 \mathrm{nM}$ and decreasing at higher doses (Demars et al., 2011).

Notably, APPs $\beta$ fails to mimic the beneficial effects of APPs $\alpha$, although there is only a difference of 16 amino acids between both proteins (Hick et al., 2015). In other studies, however, trophic effects of APPs $\beta$ were detected, albeit less potent than those of APPs $\alpha$ (Chasseigneaux et al., 2011). Interestingly, APPs $\beta$ was found to undergo further proteolytic cleavage and bind to "death receptor 6", activating caspase-6 and thus contributing to neurodegeneration (Nikolaev et al., 2009).

\section{APP Intracellular Domain (AICD)}

The intracellular domain of APP, termed AICD, interacts with various cytosolic signaling cascades including glycogen synthase kinase 3 (GSK-3), Ras proteins and MAPK pathways and is able to translocate to the nucleus after forming a complex with the adaptor protein Fe65 (Schettini et al., 2010). There, it is involved in regulation of genes associated with survival and apoptosis (Müller et al., 2008; Multhaup et al., 2015). Indeed, overexpression of AICD was found to induce apoptosis by interaction with the p53-pathway (Ozaki et al., 2006; Nakayama et al., 2008). Moreover, AICD modulates intracellular calcium homeostasis and ATP content (Hamid et al., 2007) and affects synaptic plasticity and hippocampus-dependent learning by increasing LTP (Klevanski et al., 2015).

\section{Amyloid B}

Resulting from APP cleavage by BACE-1, A $\beta$ peptides can accumulate extracellularly as soluble oligomers or in amyloid plaques, promoting neurodegeneration in AD (Haass, 2010). Interestingly, $A \beta$ can be internalized by neurons and accumulates in the cytosol as well as within endosomes/lysosomes and mitochondria (Chen and Yan, 2006). It exerts neurotoxic effects via a variety of mechanisms, such as disruption of calcium homeostasis (Berridge, 2010), overactivation of mGluR5 (Zhang et al., 2015), impairment of synaptic transmission, plasticity and network function (Kamenetz et al., 2003; Palop and Mucke, 2010), mitochondrial dysfunction (Chen and Zhong, 2013) and apoptosis (Umeda et al., 2011). Remarkably, it is also able to translocate into the nucleus and influence apoptosis-related gene transcription (Barucker et al., 2014; Multhaup et al., 2015). The APP fragment has also been suggested to form channel-like pores in neuronal membranes, but the underlying mechanisms are currently unknown (Barucker et al., 2014).

\section{LINKS BETWEEN ISCHEMIA, BRAIN INJURY AND NEURODEGENERATION-RESULTS FROM HUMAN STUDIES}

Sporadic $\mathrm{AD}$ is the most common cause of dementia and constitutes one of the most imminent medical problems in developed countries (Prince et al., 2015). Cognitive deficits in $\mathrm{AD}$ are caused by progressive loss of neurons, beginning in the temporal lobe and resulting in severe global brain atrophy (Fox and Schott, 2004). The neuronal loss is linked to pathological accumulation of amyloid and tau protein, as first described by Alzheimer (1906). No causal treatments exist at this stage of the disease. However, irreversible macroscopic pathology and cognitive decline are preceded by functional deficits such as disturbance of cellular calcium- and energy-homeostasis (Mattson, 1994), mitochondrial dysfunction (Swerdlow and Khan, 2004; Rönnbäck et al., 2016), synaptic failure (Selkoe, 2002) and activation of pro-apoptotic pathways (Mattson, 2000), offering an opportunity for detection and intervention at the preclinical stage (Jack and Holtzman, 2013). Interestingly, various lines of evidence suggest that molecular 
pathomechanisms in $\mathrm{AD}$ such as amyloid deposition and disrupted calcium homeostasis overlap with those in hypoxiaischemia (Peers et al., 2009) and TBI (Magnoni and Brody, 2010).

In many pathologies of the CNS such as TBI and stroke the brain-blood barrier $(\mathrm{BBB})$ is disturbed which results in extravasation of blood-derived proteins including albumin and inflammatory mediators into the brain tissue (Zhao et al., 2015). Presence of albumin in the extracellular space may act epileptogenic and promote degeneration (Friedman et al., 2009). Inflammatory cytokines may regulate secretase activity and both facilitate non-amyloidogenic cleavage as well as Aß deposition (Zhao et al., 2011; Yang et al., 2015), possibly contributing to the development of AD later on (Sastre et al., 2008). Alternatively, amyloid may directly diffuse from vessels into the brain tissue through a malfunctioning BBB (Pluta et al., 2009). Amyloid plaques, in turn, are well known to evoke a strong inflammatory response with activation of microglia, astrocytes and inflammatory mediators.

Amyloid accumulates and deposits into plaques if its intracellular degradation and extracellular clearance are disturbed. Proteolytic degradation is inhibited by lack of energy substrates and oxidative stress, while extracellular degradation requires intact interstitial and cerebrospinal fluid flow and BBB function and is impaired in inflammation (Iliff et al., 2015; Tarasoff-Conway et al., 2015). As these processes are disturbed in stroke and TBI, both conditions may lead to impaired amyloid clearance and $\mathrm{AD}$ development.

In line with these pathomechanisms, a history of TBI (Fleminger et al., 2003; Sivanandam and Thakur, 2012), stroke (Thiel et al., 2014) and cardiac arrest (de la Torre, 2006) are risk factors for developing $\mathrm{AD}$. Below, we will describe the similarities between these conditions in detail. Figure 1 shows the pathophysiological cascades leading from acute insult to long-term neurodegeneration.

\section{TRAUMATIC BRAIN INJURY, APP AND AD}

\section{TBI Leads to Amyloid Pathology and Strongly Increases the Risk for AD and Cognitive Decline}

TBI is a debilitating and life-threatening condition which is the leading cause of disability in people under 35 years in industrial countries (Feigin et al., 2013). Besides acute primary damage, TBI promotes secondary neurodegeneration and increases the risk for developing $\mathrm{AD}$ by $\sim 2$-fold (Mortimer et al., 1991; Mayeux et al., 1993; Schofield et al., 1997; Guo et al., 2000; Fleminger et al., 2003). Following TBI, diffuse $A \beta$ deposits can be found in the temporal cortex as early as $2 \mathrm{~h}$ after the insult (Ikonomovic et al., 2004). Furthermore, post mortem histological analysis shows that deposition of amyloid B-protein in the brain occurs in approximately one-third of individuals who die shortly after a severe head injury (Roberts et al., 1994). A $\beta$ levels are altered in cerebro-spinal and interstitial cerebral fluid in patients with TBI (Magnoni and Brody, 2010; Tsitsopoulos and Marklund, 2013) and correlate with clinical outcome (Magnoni and Brody, 2010). A history of TBI prior to the onset of dementia correlates with greater amyloid burden in patients with mild cognitive deficits (Mielke et al., 2014) and is associated with faster rates of cognitive decline in AD patients (Moretti et al., 2012; Gilbert et al., 2014). In TBI patients, APP transcription is upregulated and its axonal transport is interrupted due to diffuse axonal injury, which results in deposition of APP and its products in axonal "bulbs" (Hayashi et al., 2015). These results from human studies are in line with a large body of evidence from various models of TBI in mice, rats and sheep, where APP overexpression following TBI has been extensively studied. In models of focal cerebral injury inflicted by stabbing or weight drop local APP immunoreactivity increased in neurons as well as in astrocytes (Otsuka et al., 1991; Lewén et al., 1995, 1996). In the midline fluid percussion model of diffuse brain injury in adult rats APP expression was globally elevated in cortex and hippocampus within hours following the insult (Murakami et al., 1998); in a lateral fluid percussion model APP was overexpressed as early as $1 \mathrm{~h}$ after the insult (Pierce et al., 1996). In a weight fall model of brainstem injury in adult rats APP mRNA levels rose as soon as $1 \mathrm{~h}$ post-impact, peaked $3 \mathrm{~h}$ after the injury at almost twofold baseline level and declined to baseline within $24 \mathrm{~h}$ (Yang et al., 2014). Similarly, in an ovine TBI model APP mRNA was up-regulated as soon as $30 \mathrm{~min}$ post-impact (Van den Heuvel et al., 1999).

\section{Protective Function of APP and APPs $\alpha$ in TBI}

While over-expression of APP following mechanical insults has been observed several decades ago, the functional effects remained unclear until recently. By now, evidence from different animal models points towards an acute neuroprotective effect of APP and APPs $\alpha$ in TBI (Plummer et al., 2016). In diffuse traumatic injury in rats, intraventricular administration of $A P P s \alpha 30$ min after the insult reduced axonal injury and apoptosis and improved motor and cognitive outcome (Thornton et al., 2006). In the same model of TBI, mice lacking APP suffered from greater cognitive and motor impairment in correspondence with larger lesions and increased hippocampal cell loss as compared to WT, again suggesting a protective role of APP in TBI (Corrigan et al., 2012a). Once again, posttraumatic application of exogenous APPs $\alpha$ mitigated these deficits (Corrigan et al., 2012b). These protective effects were found to be mediated by the heparin-binding D1 and D6a domains of APPs $\alpha$ (Corrigan et al., 2011). In an additional study conducted by the same group, the neuroprotective site was pinned down to the APP96-110 sequence in D1, which, applied intraventricularly post-trauma, was enough to significantly improve histological and functional outcome (Corrigan et al., 2014).

At first glance, these findings seem to contradict exacerbation of amyloid pathology and increased risk of AD following TBI. However, there are several possibilities how the two mechanisms may be reconciled. First, APPs $\alpha$ may exert neuroprotective functions independent from the detrimental effects of $A ß$ or 


\section{Ischemic and traumatic insults}

\section{Cerebral small vessel disease Amyloidosis}

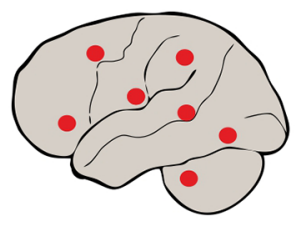

Ischemic stroke

Focal traumatic brain injury

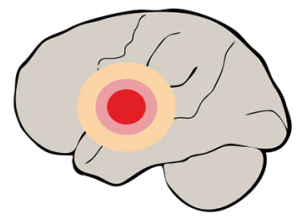

Heart failure

Circulatory collapse

Carotid occlusion

Diffuse traumatic brain injury Hypoxia

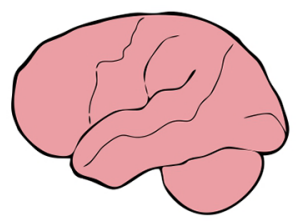

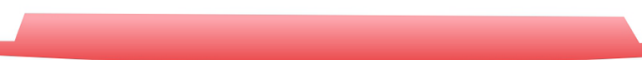
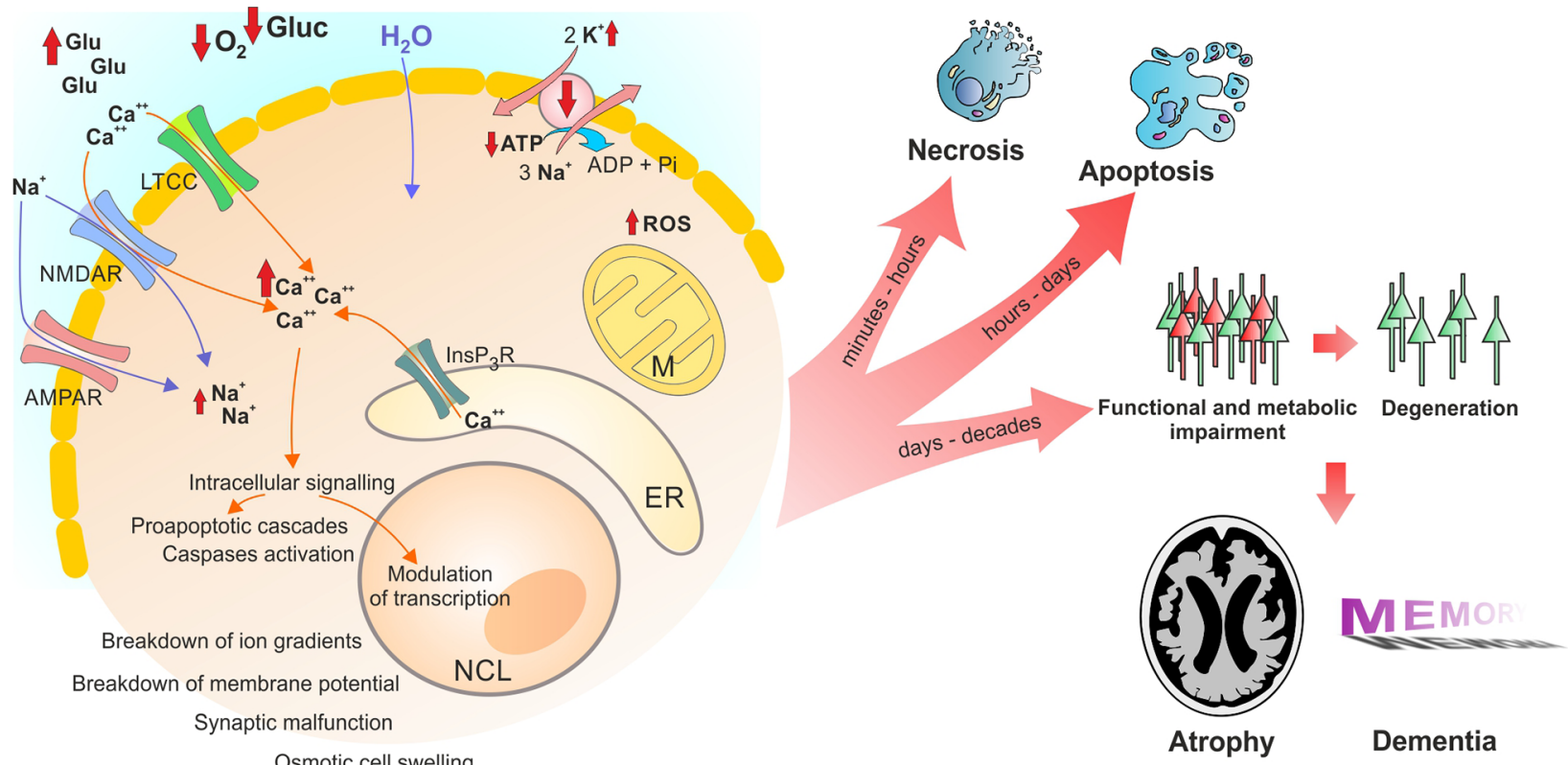

FIGURE 1 | Pathophysiological changes in neurons following acute ischemic and traumatic insults. Micro- and macroscopic focal strokes, global hypoxia-ischemia and traumatic brain injury (TBI) lead to abruption of extracellular glucose and oxygen supply and excessive glutamate release. One major shared pathomechanism is NMDAR-mediated excitotoxicity, or over-activation of NMDAR by glutamate, which facilitates sodium and calcium influx. Due to excessive ion influx, the cellular membrane potential is depolarized, which leads to activation of voltage gated calcium channels such as LTCC, initiating a vicious cycle of ion influx, calcium overload, depolarization and aberrant activity. Successively calcium from intracellular calcium stores, particularly mitochondria and the ER, is released, increasing calcium levels to up to 200 -fold of $\sim 100 \mathrm{nM}$ during resting. Calcium activates secondary messengers that are able to translocate to the nucleus and modulate gene transcription. Long-lasting or severely elevated calcium levels may lead to activation of caspases and apoptosis. Following the osmotic gradient, water enters the cell and leads to cell swelling and brain edema. Due to glucose and oxygen shortage and excessive formation of reactive oxygen species (ROS), mitochondrial function is compromised and ATP production halts. Malfunction of the energy demanding ion pumps, predominantly the sodium potassium pump, ultimately leads to breakdown of the membrane potential, a phenomenon known as anoxic or hypoxic spreading depolarization or spreading depression (due to depression of network activity in the field potential recording). Given the energy supply is timely restored, this stage can be reversed without long-lasting morphological damage. If the insult is protracted, neurons might undergo (dependent of insult's severity) necrotic or apoptotic death or degenerate with a delay of days to decades due to synaptic or metabolic malfunction. Acute cell death and delayed degeneration contribute to brain atrophy and development of dementia. Glu, glutamate; Gluc, glucose; LTCC, L-Type calcium channel; NMDAR, NMDA receptor; AMPAR, AMPA receptor; M, mitochondrion; NCL, nucleus; ER, endoplasmic reticulum; ROS, reactive oxygen species.

amyloid plaques. Second, APPs $\alpha$ could prevent deposition of $A ß$ and further growth of plaques. Third, APPs $\alpha$ may promote clearance of plaques. There is evidence for all three mechanisms. APPs $\alpha$ was shown to modulate BACE activity, possibly inhibiting amyloidogenic cleavage (Obregon et al., 2012). As described in sections "APPs $\alpha$ and APPs $\beta$ " and "Mechanisms of Neuroprotection by APP and APPs $\alpha$ Protection in HypoxiaIschemia, Excitotoxicity, Degeneration", APPs $\alpha$ counteracts Aßmediated excitotoxic damage and delayed degeneration by various trophic and regulatory effects on calcium homeostasis, synaptic function and survival pathways. Recently Fol et al. (2016) discovered that APPs $\alpha$ can ameliorate amyloid pathology 
by recruitment of microglia, underlining its involvement in clearance of amyloid.

\section{BRAIN ISCHEMIA, APP AND AD}

\section{Over-Expression, Amyloidogenic Processing of APP and Increased Risk of AD}

Cardiovascular diseases and ischemic stroke share overlapping genetic and metabolic risk factors such as hypertension, dyslipidemia, glucose intolerance or diabetes and adipositas (Arboix, 2015). Recently these risk factors were established to also increase the odds of developing AD (Orehek, 2012; Wiesmann et al., 2013; Traylor et al., 2016). Moreover, hypoxicischemic conditions of the brain such as in ischemic stroke (Honig et al., 2003), heart arrest (de la Torre, 2006), and cerebral small vessel disease (Cai et al., 2015) directly correlate with $\mathrm{AD}$ risk, suggesting that cerebrovascular dysfunction is one possible cause of the neurodegenerative disease (Humpel, 2011; Orehek, 2012). Data from a large meta-analysis (Zhou et al., 2015) and a longitudinal study with over 6500 participants (Tosto et al., 2016) show that ischemic stroke increases AD risk by about 1.6 to 2.2 -fold, respectively. Several studies indicate that, vice versa, $\mathrm{AD}$ patients have an increased risk to develop ischemic (Chi et al., 2013) and hemorrhagic (Chi et al., 2013; Tolppanen et al., 2013; Zhou et al., 2015) stroke and have a higher prevalence of cerebrovascular lesions (Jellinger, 2010). Other studies, however, did not find an increased risk of ischemic stroke in patients with $\mathrm{AD}$ (Imfeld et al., 2013; Tolppanen et al., 2013; Zhou et al., 2015). Not surprisingly, cerebrovascular disease and $\mathrm{AD}$ contribute additively to cognitive impairment in patients (Hohman et al., 2015) and mouse models (Pimentel-Coelho et al., 2013), possibly forming a vicious cycle of ischemia and neurodegeneration (Pluta et al., 2013).

It has been suggested that cerebrovascular disease, vascular dementia and $\mathrm{AD}$ share common pathophysiological cascades such as altered APP processing (Selnes et al., 2010), perturbed energy metabolism (Chen and Zhong, 2013) and pathological immune response (Brod, 2000). These common pathways may then result in overlapping histopathological findings (de la Torre, 2002; Pluta et al., 2009, 2012; Attems and Jellinger, 2014). APP overexpression and A $\beta$ deposition likely play a pivotal role in these processes. In ischemic stroke patients, expression of APP is indeed increased (Pottier et al., 2012) and serum $A \beta$ levels are elevated, correlating with infarct size and clinical outcome (Lee et al., 2005). Likewise, patients who suffered from hypoxia during a cardiac arrest present with increased $A \beta$ levels, which-again-correlate with clinical outcome (Zetterberg et al., 2011). Increased age-related deposition of $A \beta$ was also shown in chronic cerebral vascular disease in rats (Schreiber et al., 2014). However, elevation of $A \beta$ following ischemia is transient. A recent study employing Pittsburgh Compound-B positron emission tomography $\left({ }^{11} \mathrm{C}-\mathrm{PiB}-\mathrm{PET}\right.$; an in vivo imaging method of amyloid), revealed no accumulation of $\mathrm{A} \beta$ in patients 18 months after ischemic stroke (Sahathevan et al., 2016).

\section{Neuroprotective Role of APP in Ischemia in Animal Studies}

At the first glance, findings concerning APP in conditions of hypoxia/ischemia seem to be contradictory. On the one hand, the pathological role of APP is supported by multiple animal studies. On the other hand, several studies show beneficial effects of APP in animal models of hypoxia-ischemia. It can be assumed that these opposing effects are mediated by the different cleavage products of APP.

On the one hand, ischemia and oxidative stress enhance BACE-1 and $\gamma$-secretase activity, resulting in increased $A \beta$ deposition in rats and mice (Sun et al., 2006; Guglielmotto, 2009; Li et al., 2009). APP accumulates in regions of neurodegeneration following focal cerebral ischemia in the rat (Stephenson et al., 1992). Stroke in rats with $A \beta$ pathology leads to aggravated comorbidity, hippocampal atrophy, and cognitive impairment, similar to the consequences of stroke in AD patients (Amtul et al., 2014).

On the other hand, postischemic intraventricular application of APPs $\alpha$ increases neuronal survival in a model of transient focal ischemia in rats (Smith-Swintosky et al., 1994). APP-KO as well as BACE-KO mice are unable to maintain cerebral blood flow and experience drastically increased acute mortality in a model of global cerebral ischemia (Koike et al., 2012). Overexpression of APP provides neuroprotection following middle cerebral artery occlusion in rats (Clarke et al., 2007). There is compelling evidence that APP acts as a potent anti-thrombotic agent (Van Nostrand, 2016). Moreover, it is required for effective immune and glial cell responses to inflammatory stimuli (Carrano and Das, 2015). With glutamate excitotoxicity being a key pathomechanism of ischemic neuronal damage (Broughton et al., 2009), activation of ADAM10, and thus facilitation of APPs $\alpha$ production, provides neuroprotection against excitotoxic stress in vivo (Clement et al., 2008). These findings are in line with models of $\mathrm{AD}$ where expression of APPs $\alpha$ protects against neurodegeneration and rescues synaptic function (Fol et al., 2016).

Taken together, these data support the importance of balance between the beneficial APPs $\alpha$ and the neurotoxic amyloidogenic pathway, thus resolving the initially contradictive results.

\section{MECHANISMS OF NEUROPROTECTION BY APP AND APPs $\alpha$ PROTECTION IN HYPOXIA-ISCHEMIA, EXCITOTOXICITY, DEGENERATION}

As outlined in previous sections, ischemia, traumatic injury and degeneration share some common pathological cascades leading to neuronal death (see also Figure 1). One common mechanism of damage is dysregulation of calcium homeostasis (Mattson et al., 1993b; Webster et al., 2006). Intracellular calcium levels at rest are around $100 \mathrm{nM}$, and fluctuations in cytosolic calcium concentration are tightly coupled to metabolic and synaptic activity (Berridge et al., 2003). Neuronal calcium homeostasis is disturbed in $\mathrm{AD}$, with strong evidence pointing towards a pivotal role of $A \beta$ in destabilizing the balance between 
mechanisms increasing and decreasing free intracellular calcium (Khachaturian, 1994; LaFerla, 2002; Green and LaFerla, 2008; Berridge, 2010). Similarly, TBI as well as ischemic-hypoxic insults lead to drastic elevations of cellular calcium of up to $20 \mu \mathrm{M}$ (Yao and Haddad, 2004; Sun et al., 2008). Such acute, strong increases, as well as longer-lasting mild perturbations of calcium levels initiate a plethora of pathological cascades and can, finally, activate caspases and initiate apoptosis (Mattson and Chan, 2003; Orrenius et al., 2003).

APP and its metabolites, most of all APPs $\alpha$, intervene with these cascades on multiple levels and exert neuroprotective effects under various conditions of cellular stress, revealing novel possible therapeutical leverage points (Kögel et al., 2012). APPs $\alpha$ was shown to mediate neuroprotection and stabilize intracellular calcium levels in in vitro models of excitotoxicity (Mattson et al., 1993a; Ma et al., 2009). The secreted form of APP also protects against $A \beta$-mediated toxicity in rat hippocampal cell cultures by attenuating $A \beta$-mediated calcium elevation (Goodman and Mattson, 1994). In a recent study on acute hippocampal slices (Hefter et al., 2016) we showed that APP protects neuronal function in acute hypoxia and promotes recovery of neuronal activity. The protective effects were largely exerted by the APPs $\alpha$ fragment and mediated by inhibition of L-type calcium channels (LTCC). These voltage-gated calcium channels (VGCC) are beside other calcium-permeable membrane channels such as NMDA receptors (NMDAR) and internal stores major sources of intracellular calcium (Yao and Haddad, 2004; Thibault et al., 2007), thus contributing to traumatic/ischemic neuronal damage as well as to the pathophysiology underlying AD. Figure 2 summarizes major neuroprotective mechanisms of APP and APPs $\alpha$ as discussed below.

\section{Modulation of NMDA Receptors}

Traumatic and ischemic injury is marked by aberrant neuronal activity and excessive glutamate release from neurons and glia, mediating excitotoxicity through enhanced activation of glutamate receptors including the calcium-permeable NMDAR. These processes form a vicious cycle of excessive cation influx, further depolarization, opening of more channels and, eventually, breakdown of the membrane potential, osmotic cell swelling and death (Broughton et al., 2009; McAllister, 2011; see also Figure 1). Application of NMDAR blockers is an established neuroprotective strategy in models of excitotoxicity, hypoxiaischemia and TBI (Kubo et al., 2001) models. Remarkably, APPs $\alpha$ suppresses NMDAR-mediated currents (Furukawa and Mattson, 1998), potently attenuating calcium responses and thus providing protection against NMDAR-mediated excitotoxicity in hippocampal cell culture (Furukawa et al., 1996; Furukawa and Mattson, 1998; Figure 2). Seemingly contradicting these results, APPs $\alpha$ was shown to enhance LTP in acute hippocampal slices (Ring et al., 2007) as well as in vivo, where intrahippocampal application of the protein increased NMDAR currents, rescued LTP and memory performance (Taylor et al., 2008). This apparent discrepancy may be due to activation of different NMDAR subtypes which, dependent on their subcellular localization (synaptic vs. extrasynaptic) may promote either synaptic potentiation or proapoptotic effects (Hardingham

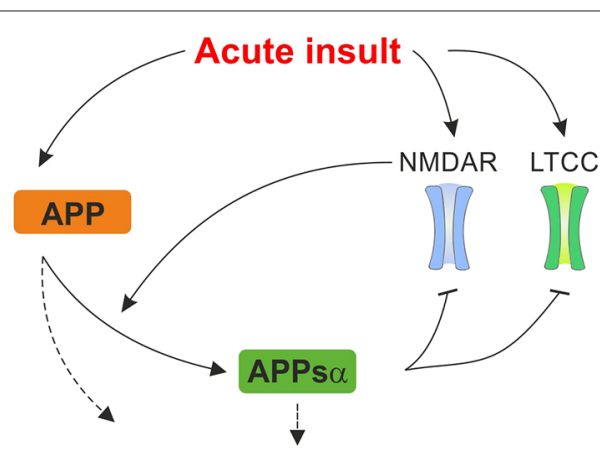

Synaptic transmission, plasticity, synaptogenesis, dendritic arborization, axonogenesis, cell adhaesion, proliferation, regulation of calcium, anti-apoptotic action on NF-kB, p53, GSK-3, CDK-5 pathways

FIGURE 2 | Simplified summary of proposed neuroprotective mechanisms of amyloid precursor protein (APP) and APPs $\alpha$ in response to acute stress. Expression of APP is upregulated in response to acute metabolic insult. As depicted in Figure 1, NMDAR and LTCC are pathologically activated, promoting excitotoxic cellular damage. Cleavage of APP is activity-dependent and $\alpha$-secretases are stimulated by NMDAR, generating the neuroprotective APPs $\alpha$ fragment. APPs $\alpha$ acts inhibitory on NMDAR and LTCC. This negative feedback mechanism may breach the vicious cycle of excitotoxicity and constitute an important protective mechanism in response to acute insults. Several further trophic, regulatory and anti-apoptotic functions of APP and APPs $\alpha$ are listed. They may contribute to acute neuroprotective effect on multiple levels. Since exact mechanisms of interaction are oftentimes not known, this ambiguity is represented by dashed arrows. The triple period below indicates that the list makes no claims of being complete since many more mechanisms are being discussed.

et al., 2002; von Engelhardt et al., 2007). In our experiments slices from wildtype mice showed postischemic potentiation of evoked population responses whereas synaptic transmission in slices from APP-KO mice was drastically reduced (Hefter et al., 2016). As this kind of plasticity also depends on NMDAR (Maggio et al., 2015), it may also be modulated by APP.

However, we could not observe involvement of NMDAR in APP-mediated protection from hypoxia. Taking into account that secretion of APPs $\alpha$ is activity-dependent (Kirazov et al., 1997; Gakhar-Koppole et al., 2008), its effects on NMDAR may provide a negative-feedback loop on extrasynaptic NMDAR in excitotoxicity or a positive feedback loop on subsynaptic NMDAR in LTP and learning.

\section{Modulation of L-Type Calcium Channels}

LTCC belong to the family of VGCC, which are-depending on the membrane potential-almost exclusively conductive for calcium (Zuccotti et al., 2011). They are one of the major sources of extracellular calcium influx in ischemia (Cataldi, 2013) and contribute to neurodegeneration in $\mathrm{AD}$ when over-activated by $\mathrm{A} \beta$ (Webster et al., 2006). The subtype $\mathrm{Ca}_{\mathrm{V}} 1.2$ has been identified as a potential pharmacotherapeutical target (Anekonda and Quinn, 2011). Several studies point towards beneficial effect of LTCC blockers in AD patients (Anekonda and Quinn, 2011; 
Lovell et al., 2015) as well as in animal models of ischemia and neurodegeneration (Gholamipour-Badie et al., 2013). APP was shown to interact directly with $\mathrm{Ca}_{\mathrm{v}} 1.2$ in cultured hippocampal and striatal inhibitory interneurons, with lack of APP resulting in aberrant activity of $\mathrm{Ca}_{\mathrm{v}} 1.2$ and altered short-term plasticity (Yang et al., 2009). In primary cultures of rat cortical neurons expression of human APP inhibited calcium oscillations by modulation of LTCC, suggesting a pivotal role in control of neuronal excitability (Santos et al., 2009). In line with these results we recently found an important role of LTCC for APP-mediated neuroprotection in hypoxia (Hefter et al., 2016). These studies suggest that regulation of LTCC function and thereby cytosolic calcium levels by APP may be neuroprotective. However, the molecular mechanisms underlying regulation of LTCC by APP, the function in healthy neurons and the role in ischemia and degeneration remain elusive.

\section{Effect of APP on Intracellular Calcium Stores}

Internal calcium stores, most importantly the ER and mitochondria, play a major role in the regulation of intracellular calcium homeostasis and contribute to elevations of calcium levels under pathological conditions (Mattson et al., 2000). Regulation of store-related calcium homeostasis appears to be mediated by the intracellular domain of APP, i.e., AICD. In cell culture studies, AICD-deficient cells show increased cytosolic calcium concentrations, decreased ability of the ER to buffer calcium and decreased levels of ATP (Hamid et al., 2007). Although a direct binding of AICD to ER receptors such as ryanodine or inositol triphosphate (IP3) receptors has not been described, indirect effects on ER stores and on calcium signaling in general are discussed. One such mechanism is modulation of phosphoinositide-regulated signaling by regulation of the PIKfyve complex, an essential kinase that synthesizes phosphatidylinositol-3,5-bisphosphate. Its loss of function results in neurodegeneration (Balklava et al., 2015; Currinn and Wassmer, 2016). APP was also proposed to modulate IP3 by affecting the transcription of GSK 3b (Hamid et al., 2007). Moreover, AICD may affect calcium levels by binding to X11, BP1, ShcA and other adaptor proteins which might link it to calcium signaling pathways (LaFerla, 2002) and regulate the expression of genes involved in calcium homeostasis such as S100a9 (Leissring et al., 2002; Pardossi-Piquard and Checler, 2012).

\section{Effect on Survival/Apoptosis Signaling Pathways and Gene Expression}

In severely compromised tissue, such as the ischemic core in stroke, neurons undergo necrosis due to osmotic swelling, lack of energy metabolites and breakdown of ion gradients (Lo et al., 2003). Under milder and longer-lasting metabolic stress, such as in the ischemic penumbra zone or in chronic cerebral hypoperfusion, the balance between anti- and proapoptotic pathways inclunding NF-кB and p53-pathways may tilt towards apoptotic death (Dirnagl et al., 1999; Broughton et al., 2009). In studies on cultured cells, APPs $\alpha$ was shown to exert anti-apoptotic effects by mechanisms such as upregulation of immediate early gene transcription factors, activation of CREB and NF- $\kappa \mathrm{B}$, genes related to cell survival (Guo et al., 1998; Ryan et al., 2013), phosphorylation of glycogen synthase kinase $3 \beta$ (GSK-3 $\beta$; Jimenez et al., 2011) or regulation of expression of cyclin-dependent kinase 5 (CDK-5; Hartl et al., 2013). Effects may be mediated by binding of APPs $\alpha$ to several different receptor proteins which are not yet unambiguously identified (Gustafsen et al., 2013). Potential targets include membranebound APP itself (Milosch et al., 2014), and direct inhibition of BACE- 1 by APPs $\alpha$ which would counteract A $\beta$-mediated neurotoxicity (Obregon et al., 2012). Further protection of amyloid toxicity by APPs $\alpha$ was mediated by increased expression of the neuroprotective proteins transthyretin and insulin-like growth factor 2 and subsequent inhibition of the proapoptotic BAD (Stein et al., 2004). AICD was described to interact with more than 20 adaptor proteins including Fe65 proteins members of the Mint/X11 family and members of the JIP family (c-jun-Nterminal kinase interacting protein, JIP1b and JIP2), translocate to the nucleus and interact with survival-related genes (PardossiPiquard and Checler, 2012).

\section{Effects on Neurogenesis and Proliferation}

Recent years have provided evidence for neurogenesis in several regions of the adult human central nervous system including the dentate gyrus, striatum and olfactory bulb. This mechanism can, in principle, enhance cognitive functions and support recovery from neuronal damage (Inta and Gass, 2015). APPs $\alpha$ was found to stimulate proliferation of neuronal progenitor cells in the subventricular zone (Caille et al., 2004) and in the hippocampus (Baratchi et al., 2012), whereas AICD was reported to have antiproliferative effects (Zhou et al., 2011). An imbalance between these APP products and thus between neurogenesis and degeneration may contribute to the development of $\mathrm{AD}$ (Zhou et al., 2011). Recently APP was shown to control adult hippocampal neurogenesis through GABAergic interneurons, regulating GABAergic synaptic transmission (Wang et al., 2014). APP's known trophic effects on neuronal viability, cell adhesion, axonogenesis, dendritic arborization and dendritic spines may also contribute to recovery from traumatic and metabolic insults and counteract degeneration (Perez et al., 1997; Lee et al., 2010). APPs $\alpha$-mediated trophic effects are activity-dependent and stimulated by activation of $5-\mathrm{HT}_{4}$ and NMDAR (GakharKoppole et al., 2008; Cochet et al., 2013), suggesting them to be a feasible adaptive strategy in LTP, plasticity and excitotoxicity.

\section{POTENTIAL THERAPEUTIC STRATEGIES}

Currently available pharmacological therapies in AD are mostly based on acetylcholine esterase inhibitors such as donepezil and rivastigmine or NMDAR blockers like memantine. They are far from eliminating the (unknown) primary cause of the disease, but do only alleviate symptoms and delay disease progression (Huang and Mucke, 2012). Likewise, immunotherapeutic approaches with antibodies against $\mathrm{A} \beta$ reduce amyloid burden, but show only limited success in the prevention of cognitive decline in ongoing phase III clinical trials (Reiman, 2016). One 


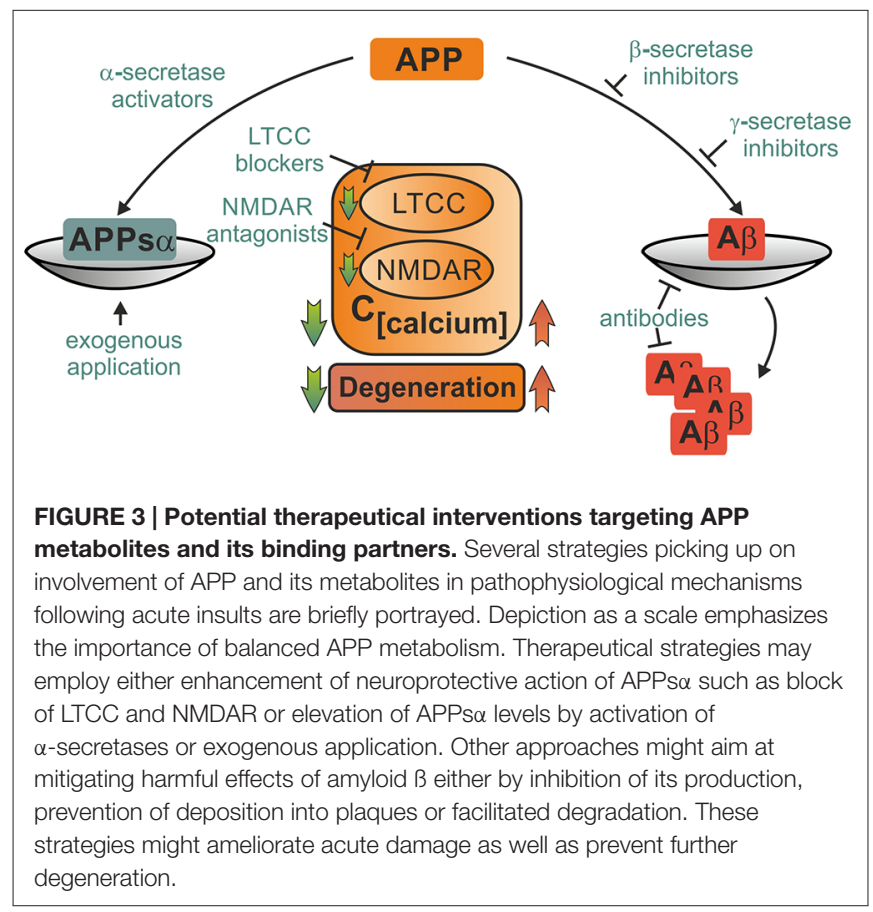

reason for the slow and tedious progress in therapy of $\mathrm{AD}$ may be that cognitive deficits in $\mathrm{AD}$ arise not only due to an excess of toxic metabolites, but also from loss of function of protective APP products. Likewise, the past two decades of research on neuroprotective strategies in ischemic stroke and TBI have been hampered by failures to translate results from bench to bedside (Hoyte et al., 2004; O'Collins et al., 2006). Mechanistic understanding of APP's role in these diseases may help to break this streak. Restitution of the perturbed balance between harmful and beneficial APP metabolites emerges as a promising neuroprotective strategy. Although the hope to find a "cure for all" seems delusive, shared pathological mechanisms in ischemia, injury and $\mathrm{AD}$ imply that discovery of common leverage points for novel drugs may be feasible. We will briefly discuss such potential therapeutic strategies which may comprise activation of $\alpha$-secretases, inhibition of $\beta$ - and $\gamma$-secretases, exogenous administration of APPs $\alpha$ or amyloid antibodies, control of cellular calcium levels by block of LTCC and NMDAR, activation of neuroprotective mechanisms and inhibition of proapoptotic downstream targets of APP (Figure 3; Selkoe, 2011).

\section{Activation of $\alpha$-Secretases}

A variety of potential strategies may shift the balance towards non-amyloidogenic cleavage of APP, including modulation of expression, trafficking and regulation of ADAM10 (Postina, 2012). Direct activation of $\alpha$-secretases by etazolate has been shown to be beneficial in TBI in mice (Siopi et al., 2013). As an indirect mechanism, activation of muscarinic M1 acetylcholine receptors has been reported to increase $\alpha$-secretase cleavage of APP and decrease Aß levels (Beach et al., 2001). Another activator of $\alpha$-secretase and inhibitor of $\beta$ - und $\gamma$-secretase is melatonin (Mukda et al., 2016). Increased dimerization of APP via specific compounds such as disulfiram was shown to shift the balance towards non-amyloidogenic cleavage products of APP and thus may present a novel therapeutic approach (Libeu et al., 2012). However, overexpression or activation of ADAM-10 may also have harmful consequences due to effects on other substrates of this enzyme (Clement et al., 2008).

\section{Inhibition of $\beta$ - and $\gamma$-Secretases}

In mice, a selective $\gamma$-secretase inhibitor has already been successfully tested, reaching a $33 \%$ reduction of $\mathrm{A} \beta$ levels within 1 week, without causing severe side effects (Basi et al., 2010). In a mouse model of TBI, pharmacological inhibition of $\gamma$-secretase activity reduced post-traumatic tissue loss and improved motor and cognitive recovery (Loane et al., 2009). Both $\gamma$ - and $\beta$-secretase process various other substrates than APP, complicating the use of respective inhibitors (John et al., 2003). However, strategies to specifically inhibit APP cleavage by BACE-1 do exist (Ben Halima et al., 2016) and first BACE-1 inhibitors made it into clinical trials (Vassar et al., 2014).

\section{Regulation of Calcium Homeostasis}

Regulation of intracellular calcium is a promising neuroprotective strategy (Duncan et al., 2010). As discussed above, APP stabilizes calcium homeostasis by interacting with LTCC, NMDAR and other signaling pathways, offering some feasible pharmacological leverage points. LTCC blockers of the dihydropyridine family such as the common antihypertensive drugs nimodipine and nifedipine attenuate progression of dementia in humans, inhibit $\mathrm{A} \beta$ formation in cell culture (Lovell et al., 2015), counteract $A \beta$-mediated calcium increase and excitotoxicity (Anekonda and Quinn, 2011) and alleviate A $\beta$ related memory deficits in animal models (Gholamipour-Badie et al., 2013). The NMDAR blocker memantine is not only an established drug for treatment of AD (Danysz and Parsons, 2012), but has also protective effects against excitotoxicity in small doses, being potentially beneficial in patients with high risk of ischemic stroke (Trotman et al., 2015). Other potential calcium-stabilizing approaches target downstream pathways of AICD (Nagase and Nakayama, 2014).

\section{Delivery of Exogenous APPs $\alpha$}

As proven in rodent models of TBI, intraventricular application of exogenous APPs $\alpha$ or its heparin binding domain promote neuronal survival and improve functional outcome (Corrigan et al., 2014). Following TBI or malignant stroke, patients often receive a decompressive craniotomy including ventricular drainage or insertion of an intracranial pressure probe. Application of APPs $\alpha$ through these entries seems feasible. However, these results are highly preliminary and it remains to be proven whether this technique is safe, beneficial and technically feasible in human patients.

\section{CONCLUSION}

The immense multitude and complexity of APP interactions and functions discovered in recent decades may seem overwhelming 
and evoke the concern to miss the forest for the trees. Nevertheless, some common principles have emerged from recent studies. APP is more than the mother molecule of amyloid, and $\mathrm{AD}$ is more than an amyloido-tauopathy. In this review article, we present convergent evidence from human studies, animal models and in vitro experiments for a neuroprotective role of APP in ischemia, brain injury and neurodegeneration. Most studies suggest that these neuroprotective and trophic effects are mainly conducted by the extracellularly secreted fragment APPs $\alpha$, whereas amyloidogenic cleavage leads to various harmful consequences. We hypothesize that under pathological conditions the cleavage balance of APP is disturbed, and loss of its neuroprotective function may contribute to disease development. While the pathological role of APP in AD may result from an overshoot of pathological products of APP (Aß), production of the neuroprotective soluble fragment APPs $\alpha$ may, in turn, reflect the normal, beneficial reaction of the organism to metabolic challenges. Therefore shifting this balance towards APPs $\alpha$ secretion may be a promising treatment strategy in $\mathrm{AD}$, stroke and TBI. Causal treatments are urgently needed in these conditions. Novel therapeutic targets arise from unraveling the mechanisms of APP-mediated neuroprotection such as regulation of cellular calcium levels by LTCC and NMDAR

\section{REFERENCES}

Alzheimer, A. (1906). Über einen eigenartigen, schweren Erkrankungsprozeß der Hirnrinde. Neurol. Cent. 23, 1129-1136.

Amtul, Z., Nikolova, S., Gao, L., Keeley, R. J., Bechberger, J. F., Fisher, A. L., et al. (2014). Comorbid A $\beta$ toxicity and stroke: hippocampal atrophy, pathology, and cognitive deficit. Neurobiol. Aging 35, 1605-1614. doi: 10.1016/j. neurobiolaging.2014.01.005

Anekonda, T. S., and Quinn, J. F. (2011). Calcium channel blocking as a therapeutic strategy for Alzheimer's disease: the case for isradipine. Biochim. Biophys. Acta 1812, 1584-1590. doi: 10.1016/j.bbadis.2011. 08.013

Arboix, A. (2015). Cardiovascular risk factors for acute stroke: risk profiles in the different subtypes of ischemic stroke. World J. Clin. Cases 3, 418-429. doi: 10.12998/wjcc.v3.i5.418

Attems, J., and Jellinger, K. A. (2014). The overlap between vascular disease and Alzheimer's disease-lessons from pathology. BMC Med. 12:206. doi: 10.1186/s12916-014-0206-2

Aydin, D., Weyer, S. W., and Müller, U. C. (2012). Functions of the APP gene family in the nervous system: insights from mouse models. Exp. Brain Res. 217, 423-434. doi: 10.1007/s00221-011-2861-2

Balklava, Z., Niehage, C., Currinn, H., Mellor, L., Guscott, B., Poulin, G., et al. (2015). The amyloid precursor protein controls PIKfyve function. PLoS One 10:e0130485. doi: 10.1371/journal.pone.0130485

Baratchi, S., Evans, J., Tate, W. P., Abraham, W. C., and Connor, B. (2012). Secreted amyloid precursor proteins promote proliferation and glial differentiation of adult hippocampal neural progenitor cells. Hippocampus 22, 1517-1527. doi: 10.1002/hipo.20988

Barucker, C., Harmeier, A., Weiske, J., Fauler, B., Albring, K. F., Prokop, S., et al. (2014). Nuclear translocation uncovers the amyloid peptide $A \beta 42$ as a regulator of gene transcription. J. Biol. Chem. 289, 20182-20191. doi: 10.1074/jbc.M114. 564690

Basi, G.S., Hemphill, S., Brigham, E.F., Liao, A., Aubele, D.L., Baker, J., et al. (2010). Amyloid precursor protein selective gamma-secretase inhibitors for treatment of Alzheimer's disease. Alzheimers Res. Ther. 2:36. doi: 10.1186/ alzrt60 inhibition, regulation of survival and apoptosis signaling pathways, trophic effects on synapto- and neurogenesis, synaptic function, plasticity and memory formation. However, current understanding of these highly complex processes and the specific contributions of APP is far from complete, and successful translation into clinic is still a major challenge. One of the reasons might be the predominant focus on histopathological endpoints in most studies in the field, largely neglecting longitudinal functional studies. Deeper comprehension of APP-related processes in living tissue, employing functional electrophysiological and imaging techniques should complement morphological studies. Combined (interventional) functional and structural evidence may help to develop new neuroprotective therapies.

\section{AUTHOR CONTRIBUTIONS}

$\mathrm{DH}$ and $\mathrm{AD}$ designed, drafted, wrote and revised this work and approved this version to be published. DH designed and created the figures.

\section{FUNDING}

This study was supported by the DFG Research Group 1332.

Beach, T. G., Walker, D. G., Potter, P. E., Sue, L. I., and Fisher, A. (2001) Reduction of cerebrospinal fluid amyloid $\beta$ after systemic administration of M1 muscarinic agonists. Brain Res. 905, 220-223. doi: 10.1016/S00068993(01)02484-2

Bell, K. F. S., Zheng, L., Fahrenholz, F., and Cuello, A. C. (2008). ADAM10 over-expression increases cortical synaptogenesis. Neurobiol. Aging 29, 554-565. doi: 10.1016/j.neurobiolaging.2006.11.004

Ben Halima, S., Mishra, S., Raja, K. M. P., Willem, M., Baici, A., Simons, K., et al. (2016). Specific inhibition of $\beta$-secretase processing of the Alzheimer disease amyloid precursor protein. Cell Rep. 14, 2127-2141. doi: 10.1016/j.celrep.2016. 01.076

Berridge, M. J. (2010). Calcium hypothesis of Alzheimer's disease. Pflugers Arch. 459, 441-449. doi: 10.1007/s00424-009-0736-1

Berridge, M. J., Bootman, M. D., and Roderick, H. L. (2003). Calcium signalling: dynamics, homeostasis and remodelling. Nat. Rev. Mol. Cell Biol. 4, 517-529. doi: 10.1038/nrm1155

Beyreuther, K., Pollwein, P., Multhaup, G., Mönning, U., König, G., Dyrks, T., et al. (1993). Regulation and expression of the Alzheimer's $\beta / \mathrm{A} 4$ amyloid protein precursor in health, disease and Down's syndrome. Ann. N Y Acad. Sci. 695, 91-102. doi: 10.1111/j.1749-6632.1993. tb23035.x

Bourdet, I., Preat, T., and Goguel, V. (2015). The full-length form of the Drosophila amyloid precursor protein is involved in memory formation. J. Neurosci. 35, 1043-1051. doi: 10.1523/JNEUROSCI.2093-14.2015

Brod, S. A. (2000). Unregulated inflammation shortens human functional longevity. Inflamm. Res. 49, 561-570. doi: 10.1007/s000110050632

Broughton, B. R. S., Reutens, D. C., and Sobey, C. G. (2009). Apoptotic mechanisms after cerebral ischemia. Stroke 40, e331-e339. doi: 10.1161/strokeaha.108.531632

Brunholz, S., Sisodia, S., Lorenzo, A., Deyts, C., Kins, S., and Morfini, G. (2012). Axonal transport of APP and the spatial regulation of APP cleavage and function in neuronal cells. Exp. Brain Res. 217, 353-364. doi: 10.1007/s00221011-2870-1

Cai, Z., Wang, C., He, W., Tu, H., Tang, Z., Xiao, M., et al. (2015). Cerebral small vessel disease and Alzheimer's disease. Clin. Interv. Aging 10, 1695-1704. doi: 10.2147/CIA.S90871 
Caillé, I., Allinquant, B., Dupont, E., Bouillot, C., Langer, A., Müller, U., et al. (2004). Soluble form of amyloid precursor protein regulates proliferation of progenitors in the adult subventricular zone. Development 131, 2173-2181. doi: $10.1242 /$ dev.01103

Caldwell, J. H., Klevanski, M., Saar, M., and Müller, U. C. (2013). Roles of the amyloid precursor protein family in the peripheral nervous system. Mech. Dev. 130, 433-446. doi: 10.1016/j.mod.2012.11.001

Caporaso, G. L., Takei, K., Gandy, S. E., Matteoli, M., Mundigl, O., Greengard, P., et al. (1994). Morphologic and biochemical analysis of the intracellular trafficking of the Alzheimer beta/A4 amyloid precursor protein. J. Neurosci. 14, 3122-3138.

Carrano, A., and Das, P. (2015). Altered innate immune and glial cell responses to inflammatory stimuli in amyloid precursor protein knockout mice. PLoS One 10:e0140210. doi: 10.1371/journal.pone.0140210

Cataldi, M. (2013). The changing landscape of voltage-gated calcium channels in neurovascular disorders and in neurodegenerative diseases. Curr. Neuropharmacol. 11, 276-297. doi: 10.2174/1570159x11311030004

Chasseigneaux, S., Dinc, L., Rose, C., Chabret, C., Coulpier, F., Topilko, P., et al. (2011). Secreted amyloid precursor protein $\beta$ and secreted amyloid precursor protein alpha induce axon outgrowth in vitro through Egrl signaling pathway. PLoS One 6:e16301. doi: 10.1371/journal.pone.0016301

Chen, X., and Yan, S. D. (2006). Mitochondrial A $\beta$ : a potential cause of metabolic dysfunction in Alzheimer's disease. IUBMB Life 58, 686-694. doi: 10.1080/15216540601047767

Chen, Z., and Zhong, C. (2013). Decoding Alzheimer's disease from perturbed cerebral glucose metabolism: implications for diagnostic and therapeutic strategies. Prog. Neurobiol. 108, 21-43. doi: 10.1016/j.pneurobio.2013.06.004

Chi, N.-F., Chien, L.-N., Ku, H.-L., Hu, C.-J., and Chiou, H.-Y. (2013). Alzheimer disease and risk of stroke. Neurology 80, 705-711. doi: 10.1212/WNL. 0b013e31828250af

Cirrito, J. R., Yamada, K. A., Finn, M. B., Sloviter, R. S., Bales, K. R., May, P. C., et al. (2005). Synaptic activity regulates interstitial fluid amyloid- $\beta$ levels in vivo. Neuron 48, 913-922. doi: 10.1016/j.neuron.2005.10.028

Clarke, J., Thornell, A., Corbett, D., Soininen, H., Hiltunen, M., and Jolkkonen, J. (2007). Overexpression of APP provides neuroprotection in the absence of functional benefit following middle cerebral artery occlusion in rats. Eur. J. Neurosci. 26, 1845-1852. doi: 10.1111/j.1460-9568.2007.05807.x

Clement, A. B., Hanstein, R., Schröder, A., Nagel, H., Endres, K., Fahrenholz, F., et al. (2008). Effects of neuron-specific ADAM10 modulation in an in vivo model of acute excitotoxic stress. Neuroscience 152, 459-468. doi: 10.1016/j. neuroscience.2007.10.060

Cochet, M., Donneger, R., Cassier, E., Gaven, F., Lichtenthaler, S. F., Marin, P., et al. (2013). 5- $\mathrm{HT}_{4}$ receptors constitutively promote the non-amyloidogenic pathway of APP cleavage and interact with ADAM10. ACS Chem. Neurosci. 4, 130-140. doi: 10.1021/cn300095t

Corrigan, F., Pham, C. L., Vink, R., Blumbergs, P. C., Masters, C. L., van den Heuvel, C., et al. (2011). The neuroprotective domains of the amyloid precursor protein, in traumatic brain injury, are located in the two growth factor domains. Brain Res. 1378, 137-143. doi: 10.1016/j.brainres.2010.12.077

Corrigan, F., Thornton, E., Roisman, L. C., Leonard, A. V., Vink, R., Blumbergs, P. C., et al. (2014). The neuroprotective activity of the amyloid precursor protein against traumatic brain injury is mediated via the heparin binding site in residues 96-110. J. Neurochem. 128, 196-204. doi: 10.1111/jnc. 12391

Corrigan, F., Vink, R., Blumbergs, P. C., Masters, C. L., Cappai, R., and van den Heuvel, C. (2012a). Characterisation of the effect of knockout of the amyloid precursor protein on outcome following mild traumatic brain injury. Brain Res. 1451, 87-99. doi: 10.1016/j.brainres.2012.02.045

Corrigan, F., Vink, R., Blumbergs, P. C., Masters, C. L., Cappai, R., and van den Heuvel, C. (2012b). sAPP $\alpha$ rescues deficits in amyloid protein knockout mice following focal traumatic brain injury. J. Neurochem. 122, 208-220. doi: 10.1111/j.1471-4159.2012.07761.x

Currinn, H., and Wassmer, T. (2016). The amyloid precursor protein (APP) binds the PIKfyve complex and modulates its function. Biochem. Soc. Trans. 44, 185-190. doi: 10.1042/BST20150179

Danysz, W., and Parsons, C. G. (2012). Alzheimer's disease, $\beta$-amyloid, glutamate, NMDA receptors and memantine-searching for the connections. Br. J. Pharmacol. 167, 324-352. doi: 10.1111/j.1476-5381.2012.02057.x
Del Turco, D., Paul, M. H., Schlaudraff, J., Hick, M., Endres, K., Müller, U. C., et al. (2016). Region-specific differences in amyloid precursor protein expression in the mouse hippocampus. Front. Mol. Neurosci. 9:134. doi: 10.3389/fnmol.2016. 00134

Demars, M. P., Bartholomew, A., Strakova, Z., and Lazarov, O. (2011). Soluble amyloid precursor protein: a novel proliferation factor of adult progenitor cells of ectodermal and mesodermal origin. Stem Cell Res. Ther. 2:36. doi: $10.1186 /$ scrt77

Dirnagl, U., Iadecola, C., and Moskowitz, M. A. (1999). Pathobiology of ischaemic stroke: an integrated view. Trends Neurosci. 22, 391-397. doi: 10.1016/s01662236(99)01401-0

Duncan, R. S., Goad, D. L., Grillo, M. A., Kaja, S., Payne, A. J., and Koulen, P. (2010). Control of intracellular calcium signaling as a neuroprotective strategy. Molecules 15, 1168-1195. doi: 10.3390/molecules15031168

Dunning, C. J. R., Black, H. L., Andrews, K. L., Davenport, E. C., Conboy, M., Chawla, S., et al. (2016). Multisite tyrosine phosphorylation of the $\mathrm{N}$-terminus of Mint1/X11 $\alpha$ by Src kinase regulates the trafficking of amyloid precursor protein. J. Neurochem. 137, 518-527. doi: 10.1111/jnc.13571

von Engelhardt, J., Coserea, I., Pawlak, V., Fuchs, E. C., Köhr, G., Seeburg, P. H., et al. (2007). Excitotoxicity in vitro by NR2A- and NR2B-containing NMDA receptors. Neuropharmacology 53, 10-17. doi: 10.1016/j.neuropharm.2007. 04.015

Feigin, V. L., Theadom, A., Barker-Collo, S., Starkey, N. J., McPherson, K., Kahan, M., et al. (2013). Incidence of traumatic brain injury in New Zealand: a population-based study. Lancet Neurol. 12, 53-64. doi: 10.1016/S14744422(12)70262-4

Fleminger, S., Oliver, D. L., Lovestone, S., Rabe-Hesketh, S., and Giora, A. (2003). Head injury as a risk factor for Alzheimer's disease: the evidence 10 years on; a partial replication. J. Neurol. Neurosurg. Psychiatry 74, 857-862. doi: 10.1136/jnnp.74.7.857

Fol, R., Braudeau, J., Ludewig, S., Abel, T., Weyer, S., Roederer, J.-P., et al. (2016). Viral gene transfer of APPs $\alpha$ rescues synaptic failure in an Alzheimer's disease mouse model. Acta Neuropathol. 131, 247-266. doi: 10.1007/s00401-0151498-9

Fox, N. C., and Schott, J. M. (2004). Imaging cerebral atrophy: normal ageing to Alzheimer's disease. Lancet 363, 392-394. doi: 10.1016/s0140-6736(04)15441-x

Friedman, A., Kaufer, D., and Heinemann, U. (2009). Blood-brain barrier breakdown-inducing astrocytic transformation: novel targets for the prevention of epilepsy. Epilepsy Res. 85, 142-149. doi: 10.1016/j.eplepsyres. 2009.03.005

Furukawa, K., and Mattson, M. P. (1998). Secreted amyloid precursor protein $\alpha$ selectively suppresses N-methyl-d-aspartate currents in hippocampal neurons: involvement of cyclic GMP. Neuroscience 83, 429-438. doi: 10.1016/s03064522(97)00398-9

Furukawa, K., Sopher, B. L., Rydel, R. E., Begley, J. G., Pham, D. G., Martin, G. M., et al. (1996). Increased activity-regulating and neuroprotective efficacy of $\alpha$-secretase-derived secreted amyloid precursor protein conferred by a C-terminal heparin-binding domain. J. Neurochem. 67, 1882-1896. doi: 10.1046/j.1471-4159.1996.67051882.x

Gakhar-Koppole, N., Hundeshagen, P., Mandl, C., Weyer, S. W., Allinquant, B., Müller, U., et al. (2008). Activity requires soluble amyloid precursor protein $\alpha$ to promote neurite outgrowth in neural stem cell-derived neurons via activation of the MAPK pathway. Eur. J. Neurosci. 28, 871-882. doi: 10.1111/j. 1460-9568.2008.06398.x

Gholamipour-Badie, H., Naderi, N., Khodagholi, F., Shaerzadeh, F., and Motamedi, F. (2013). L-type calcium channel blockade alleviates molecular and reversal spatial learning and memory alterations induced by entorhinal amyloid pathology in rats. Behav. Brain Res. 237, 190-199. doi: 10.1016/j.bbr.2012.09. 045

Gilbert, M., Snyder, C., Corcoran, C., Norton, M. C., Lyketsos, C. G., and Tschanz, J. T. (2014). The association of traumatic brain injury with rate of progression of cognitive and functional impairment in a population-based cohort of Alzheimer's disease: the Cache County dementia progression study. Int. Psychogeriatr. 26, 1593-1601. doi: 10.1017/S1041610214 000842

Goodman, Y., and Mattson, M. P. (1994). Secreted forms of $\beta$-amyloid precursor protein protect hippocampal neurons against amyloid $\beta$-peptide-induced oxidative injury. Exp. Neurol. 128, 1-12. doi: 10.1006/exnr.1994.1107 
Gralle, M., and Ferreira, S. T. (2007). Structure and functions of the human amyloid precursor protein: the whole is more than the sum of its parts. Prog. Neurobiol. 82, 11-32. doi: 10.1016/j.pneurobio.2007. 02.001

Green, K. N., and LaFerla, F. M. (2008). Linking calcium to $A \beta$ and Alzheimer's disease. Neuron 59, 190-194. doi: 10.1016/j.neuron.2008.07.013

Guglielmotto, M. (2009). The up-regulation of BACE1 mediated by hypoxia and ischemic injury: role of oxidative stress and HIF $\alpha$. J. Neurochem. 108, 1045-1056. doi: 10.1111/j.1471-4159.2008.05858.x

Guo, Z., Cupples, L. A., Kurz, A., Auerbach, S. H., Volicer, L., Chui, H., et al. (2000). Head injury and the risk of AD in the MIRAGE study. Neurology 54, 1316-1323. doi: 10.1212/wnl.54.6.1316

Guo, Q., Robinson, N., and Mattson, M. P. (1998). Secreted $\beta$-amyloid precursor protein counteracts the proapoptotic action of mutant presenilin-1 by activation of NF-kappaB and stabilization of calcium homeostasis. J. Biol. Chem. 273, 12341-12351. doi: 10.1074/jbc.273.20.12341

Gustafsen, C., Glerup, S., Pallesen, L. T., Olsen, D., Andersen, O. M., Nykjær, A., et al. (2013). Sortilin and SorLA display distinct roles in processing and trafficking of amyloid precursor protein. J. Neurosci. 33, 64-71. doi: 10.1523/JNEUROSCI.2371-12.2013

Haass, C. (2010). Initiation and propagation of neurodegeneration. Nat. Med. 16, 1201-1204. doi: 10.1038/nm.2223

Haass, C., Kaether, C., Thinakaran, G., and Sisodia, S. (2012). Trafficking and proteolytic processing of APP. Cold Spring Harb. Perspect. Med. 2:a006270. doi: 10.1101/cshperspect.a006270

Hamid, R., Kilger, E., Willem, M., Vassallo, N., Kostka, M., Bornhövd, C., et al. (2007). Amyloid precursor protein intracellular domain modulates cellular calcium homeostasis and ATP content. J. Neurochem. 102, 1264-1275. doi: $10.1111 / j .1471-4159.2007 .04627 . x$

Hardingham, G. E., Fukunaga, Y., and Bading, H. (2002). Extrasynaptic NMDARs oppose synaptic NMDARs by triggering CREB shut-off and cell death pathways. Nat. Neurosci. 5, 405-414. doi: 10.1038/nn835

Hardy, J., and Selkoe, D. J. (2002). The amyloid hypothesis of Alzheimer's disease: progress and problems on the road to therapeutics. Science 297, 353-356. doi: 10.1126/science.1072994

Hartl, D., Klatt, S., Roch, M., Konthur, Z., Klose, J., Willnow, T. E., et al. (2013). Soluble alpha-APP (sAPPalpha) regulates CDK5 xxpression and activity in neurons. PLoS One 8:e65920. doi: 10.1371/journal.pone.0065920

Hayashi, T., Ago, K., Nakamae, T., Higo, E., and Ogata, M. (2015). Two different immunostaining patterns of beta-amyloid precursor protein (APP) may distinguish traumatic from nontraumatic axonal injury. Int. J. Legal Med. 129, 1085-1090. doi: 10.1007/s00414-015-1245-8

Heber, S., Herms, J., Gajic, V., Hainfellner, J., Aguzzi, A., Rülicke, T., et al. (2000). Mice with combined gene knock-outs reveal essential and partially redundant functions of amyloid precursor protein family members. J. Neurosci. 20, 7951-7963.

Hefter, D., Kaiser, M., Weyer, S. W., Papageorgiou, I. E., Both, M., Kann, O., et al. (2016). Amyloid precursor protein protects neuronal network function after hypoxia via control of voltage-gated calcium channels. J. Neurosci. 36, 8356-8371. doi: 10.1523/JNEUROSCI.4130-15.2016

Herbst-Robinson, K. J., Liu, L., James, M., Yao, Y., Xie, S. X., and Brunden, K. R. (2015). Inflammatory eicosanoids increase amyloid precursor protein expression via activation of multiple neuronal receptors. Sci. Rep. 5:18286. doi: 10.1038/srep18286

Herms, J., Anliker, B., Heber, S., Ring, S., Fuhrmann, M., Kretzschmar, H., et al. (2004). Cortical dysplasia resembling human type 2 lissencephaly in mice lacking all three APP family members. EMBO J. 23, 4106-4115. doi: 10.1038/sj. emboj.7600390

Van den Heuvel, C., Blumbergs, P. C., Finnie, J. W., Manavis, J., Jones, N. R., Reilly, P. L., et al. (1999). Upregulation of amyloid precursor protein messenger RNA in response to traumatic brain injury: an ovine head impact model. Exp. Neurol. 159, 441-450. doi: 10.1006/exnr.1999.7150

Hick, M., Herrmann, U., Weyer, S. W., Mallm, J.-P., Tschäpe, J.-A., Borgers, M., et al. (2015). Acute function of secreted amyloid precursor protein fragment APPs $\alpha$ in synaptic plasticity. Acta Neuropathol. 129, 21-37. doi: $10.1007 / \mathrm{s} 00401-014-1368-\mathrm{x}$

Hohman, T. J., Samuels, L. R., Liu, D., Gifford, K. A., Mukherjee, S., Benson, E. M., et al. (2015). Stroke risk interacts with Alzheimer's disease biomarkers on brain aging outcomes. Neurobiol. Aging 36, 2501-2508. doi: 10.1016/j. neurobiolaging.2015.05.021

Honig, L. S., Tang, M.-X., Albert, S., Costa, R., Luchsinger, J., Manly, J., et al. (2003). Stroke and the risk of Alzheimer disease. Arch. Neurol. 60, 1707-1712. doi: 10.1001/archneur.60.12.1707

Hornsten, A., Lieberthal, J., Fadia, S., Malins, R., Ha, L., Xu, X., et al. (2007). APL-1, a Caenorhabditis elegans protein related to the human $\beta$-amyloid precursor protein, is essential for viability. Proc. Natl. Acad. Sci. U S A 104, 1971-1976. doi: $10.1073 /$ pnas.0603997104

Hoyer, A., Bardenheuer, H. J., Martin, E., and Plaschke, K. (2005). Amyloid precursor protein (APP) and its derivatives change after cellular energy depletion. An in vitro-study. J. Neural Transm. 112, 239-253. doi: 10.1007/s00702-004-0176-1

Hoyte, L., Kaur, J., and Buchan, A. M. (2004). Lost in translation: taking neuroprotection from animal models to clinical trials. Exp. Neurol. 188, 200-204. doi: 10.1016/j.expneurol.2004.05.008

Huang, Y., and Mucke, L. (2012). Alzheimer mechanisms and therapeutic strategies. Cell 148, 1204-1222. doi: 10.1016/j.cell.2012.02.040

Humpel, C. (2011). Chronic mild cerebrovascular dysfunction as a cause for Alzheimer's disease? Exp. Gerontol. 46, 225-232. doi: 10.1016/j.exger.2010. 11.032

Ikonomovic, M. D., Uryu, K., Abrahamson, E. E., Ciallella, J. R., Trojanowski, J. Q., Lee, V. M. Y., et al. (2004). Alzheimer's pathology in human temporal cortex surgically excised after severe brain injury. Exp. Neurol. 190, 192-203. doi: 10.1016/j.expneurol.2004.06.011

Iliff, J. J., Goldman, S. A., and Nedergaard, M. (2015). Implications of the discovery of brain lymphatic pathways. Lancet Neurol. 14, 977-979. doi: 10.1016/s14744422(15)00221-5

Imfeld, P., Bodmer, M., Schuerch, M., Jick, S. S., and Meier, C. R. (2013). Risk of incident stroke in patients with Alzheimer disease or vascular dementia. Neurology 81, 910-919. doi: 10.1212/WNL.0b013e3182a35151

Inta, D., and Gass, P. (2015). Is forebrain neurogenesis a potential repair mechanism after stroke? J. Cereb. Blood Flow Metab. 35, 1220-1221. doi: $10.1038 / \mathrm{jcbfm} .2015 .95$

Jack, C. R., and Holtzman, D. M. (2013). Biomarker modeling of Alzheimer's disease. Neuron 80, 1347-1358. doi: 10.1016/j.neuron.2013.12.003

Jedlicka, P., Owen, M., Vnencak, M., Tschäpe, J. A., Hick, M., Müller, U. C., et al. (2012). Functional consequences of the lack of amyloid precursor protein in the mouse dentate gyrus in vivo. Exp. Brain Res. 217, 441-447. doi: 10.1007/s00221011-2911-9

Jellinger, K. A. (2010). Prevalence and impact of cerebrovascular lesions in Alzheimer and lewy body diseases. Neurodegener. Dis. 7, 112-115. doi: $10.1159 / 000285518$

Jimenez, S., Torres, M., Vizuete, M., Sanchez-Varo, R., Sanchez-Mejias, E., Trujillo-Estrada, L., et al. (2011). Age-dependent accumulation of soluble amyloid $\beta(A \beta)$ oligomers reverses the neuroprotective effect of soluble amyloid precursor protein-alpha $(\operatorname{sAPP}(\alpha))$ by modulating phosphatidylinositol 3-kinase (PI3K)/Akt-GSK-3 $\beta$ pathway in Alzheimer mouse m. J. Biol. Chem. 286, 18414-18425. doi: 10.1074/jbc.m110.209718

John, V., Beck, J. P., Bienkowski, M. J., Sinha, S., and Heinrikson, R. L. (2003). Human B-secretase (BACE) and BACE inhibitors. J. Med. Chem. 46, 4625-4630. doi: 10.1021/jm030247h

Jung, E. S., Hong, H., Kim, C., Mook-Jung, I., and Inhee, M.-J. (2015). Acute ER stress regulates amyloid precursor protein processing through ubiquitin-dependent degradation. Sci. Rep. 5:8805. doi: 10.1038/srep 08805

Kamenetz, F., Tomita, T., Hsieh, H., Seabrook, G., Borchelt, D., Iwatsubo, T., et al. (2003). APP processing and synaptic function. Neuron 37, 925-937. doi: 10.1016/s0896-6273(03)00124-7

Kang, J., Lemaire, H.-G., Unterbeck, A., Salbaum, J. M., Masters, C. L., Grzeschik, K.-H., et al. (1987). The precursor of Alzheimer's disease amyloid A4 protein resembles a cell-surface receptor. Nature 325, 733-736. doi: $10.1038 / 325733 \mathrm{a} 0$

van der Kant, R., and Goldstein, L. S. B. (2015). Cellular functions of the amyloid precursor protein from development to dementia. Dev. Cell 32, 502-515. doi: 10.1016/j.devcel.2015.01.022

Khachaturian, Z. S. (1994). Calcium hypothesis of Alzheimer's disease and brain aging. Ann. N Y Acad. Sci. 15, 1-11. doi: 10.111/j.1749-6632.1994.tb44398.x 
Kirazov, L., Löffler, T., Schliebs, R., and Bigl, V. (1997). Glutamate-stimulated secretion of amyloid precursor protein from cortical rat brain slices. Neurochem 30, 557-563. doi: 10.1016/s0197-0186(96)00119-2

Klevanski, M., Herrmann, U., Weyer, S. W., Fol, R., Cartier, N., Wolfer, D. P., et al. (2015). The APP intracellular domain is required for normal synaptic morphology, synaptic plasticity and hippocampus-dependent behavior. J. Neurosci. 35, 16018-16033. doi: 10.1523/JNEUROSCI.200915.2015

Kögel, D., Deller, T., and Behl, C. (2012). Roles of amyloid precursor protein family members in neuroprotection, stress signaling and aging. Exp. Brain Res. 217, 471-479. doi: 10.1007/s00221-011-2932-4

Kohli, B. M., Pflieger, D., Mueller, L. N., Carbonetti, G., Aebersold, R., Nitsch, R. M., et al. (2012). Interactome of the amyloid precursor protein APP in brain reveals a protein network involved in synaptic vesicle turnover and a close association with Synaptotagmin-1. J. Proteome Res. 11, 4075-4090. doi: $10.1021 /$ pr300123g

Koike, M. A., Lin, A. J., Pham, J., Nguyen, E., Yeh, J. J., Rahimian, R., et al. (2012). APP knockout mice experience acute mortality as the result of ischemia. PLoS One 7:e42665. doi: 10.1371/journal.pone.0042665

Korte, M., Herrmann, U., Zhang, X., and Draguhn, A. (2012). The role of APP and APLP for synaptic transmission, plasticity and network function: lessons from genetic mouse models. Exp. Brain Res. 217, 435-440. doi: 10.1007/s00221-0112894-6

Kubo, T., Yokoi, T., Hagiwara, Y., Fukumori, R., Goshima, Y., and Misu, Y. (2001). Characteristics of protective effects of NMDA antagonist and calcium channel antagonist on ischemic calcium accumulation in rat hippocampal CA1 region. Brain Res. Bull. 54, 413-419. doi: 10.1016/s0361-9230(01)00429-4

Laßek, M., Weingarten, J., Wegner, M., and Volknandt, W. (2016). The amyloid precursor protein-A novel player within the molecular array of presynaptic nanomachines. Front. Synaptic Neurosci. 7:21. doi: 10.3389/fnsyn.2015. 00021

LaFerla, F. M. (2002). Calcium dyshomeostasis and intracellular signalling in Alzheimer's disease. Nat. Rev. Neurosci. 3, 862-872. doi: 10.1038/nrn960

Lee, P. H., Bang, O. Y., Hwang, E. M., Lee, J. S., Joo, U. S., Mook-Jung, I., et al. (2005). Circulating beta amyloid protein is elevated in patients with acute ischemic stroke. J. Neural Transm. 112, 1371-1379. doi: 10.1007/s00702-0040274-0

Lee, K. J., Moussa, C. E. H., Lee, Y., Sung, Y., Howell, B. W., Turner, R. S., et al. (2010). Beta amyloid-independent role of amyloid precursor protein in generation and maintenance of dendritic spines. Neuroscience 169, 344-356. doi: 10.1016/j.neuroscience.2010.04.078

Leissring, M. A., Murphy, M. P., Mead, T. R., Akbari, Y., Sugarman, M. C., Jannatipour, M., et al. (2002). A physiologic signaling role for the gamma secretase-derived intracellular fragment of APP. Proc. Natl. Acad. Sci. U S A 99, 4697-4702. doi: 10.1073/pnas.072033799

Lewén, A., Li, G. L., Nilsson, P., Olsson, Y., and Hillered, L. (1995). Traumatic brain injury in rat produces changes of beta-amyloid precursor protein immunoreactivity. Neuroreport. 6, 357-360. doi: 10.1097/00001756199501000-00032

Lewén, A., Li, G. L., Olsson, Y., and Hillered, L. (1996). Changes in microtubuleassociated protein 2 and amyloid precursor protein immunoreactivity following traumatic brain injury in rat: influence of MK-801 treatment. Brain Res. 719, 161-171. doi: 10.1016/0006-8993(96)00081-9

Li, L., Zhang, X., Yang, D., Luo, G., Chen, S., and Le, W. (2009). Hypoxia increases $\mathrm{A} \beta$ generation by altering $\beta$ - and $\gamma$-cleavage of APP. Neurobiol. Aging 30, 1091-1098. doi: 10.1016/j.neurobiolaging.2007.10.011

Liao, M.-C., Muratore, C. R., Gierahn, T. M., Sullivan, S. E., Srikanth, P., De Jager, P. L., et al. (2016). Single-cell detection of secreted A $\beta$ and $\operatorname{sAPP} \alpha$ from human IPSC-derived neurons and astrocytes. J. Neurosci. 36, 1730-1746. doi: 10.1523/JNEUROSCI.2735-15.2016

Libeu, C. A. P., Descamps, O., Zhang, Q., John, V., and Bredesen, D. E. (2012). Altering APP proteolysis: increasing sAPPalpha production by targeting dimerization of the APP Ectodomain. PLoS One 7:e40027. doi: 10.1371/journal. pone.0040027

Lo, E. H., Dalkara, T., and Moskowitz, M. A. (2003). Mechanisms, challenges and opportunities in stroke. Nat. Rev. Neurosci. 4, 399-415. doi: 10.1038/nrn1106

Loane, D. J., Pocivavsek, A., Moussa, C. E.-H., Thompson, R., Matsuoka, Y., Faden, A. I., et al. (2009). Amyloid precursor protein secretases as therapeutic targets for traumatic brain injury. Nat. Med. 15, 377-379. doi: 10.1038/ nm. 1940

Lovell, M. A., Abner, E., Kryscio, R., Xu, L., Fister, S. X., and Lynn, B. C. (2015). Calcium channel blockers, progression to dementia, and effects on amyloid beta peptide production. Oxid. Med. Cell. Longev. 2015:787805. doi: 10.1155/2015/787805

Ma, T., Zhao, Y., Kwak, Y. D., Yang, Z., Thompson, R., Luo, Z., et al. (2009). Statin's excitoprotection is mediated by sAPP and the subsequent attenuation of calpain-induced truncation events, likely via rho-ROCK signaling. J. Neurosci. 29, 11226-11236. doi: 10.1523/JNEUROSCI.6150-08. 2009

Maggio, N., Shavit Stein, E., and Segal, M. (2015). Ischemic LTP: NMDA-dependency and dorso/ventral distribution within the hippocampus. Hippocampus 25, 1465-1471. doi: 10.1002/hipo.22467

Magnoni, S., and Brody, D. (2010). New perspectives on amyloid- $\beta$ dynamics after acute brain injury: moving between experimental approaches and studies in the human brain. Arch. Neurol. 67, 1068-1073. doi: 10.1001/archneurol. 2010.214

Mattson, M. P. (1994). Calcium and neuronal injury in Alzheimer's disease. Contributions of $\beta$-amyloid precursor protein mismetabolism, free radicals and metabolic compromise. Ann. N Y Acad. Sci. 747, 50-76. doi: 10.1111/j.17496632.1994.tb44401.x

Mattson, M. P. (2000). Apoptosis in neurodegenerative disorders. Nat. Rev. Mol. Cell Biol. 1, 120-130. doi: 10.1038/35040009

Mattson, M. P., and Chan, S. L. (2003). Calcium orchestrates apoptosis. Nat. Cell Biol. 5, 1041-1043. doi: 10.1038/ncb1203-1041

Mattson, M. P., Cheng, B., Culwell, A. R., Esch, F. S., Lieberburg, I., and Rydel, R. E. (1993a). Evidence for excitoprotective and intraneuronal calcium-regulating roles for secreted forms of the $\beta$-amyloid precursor protein. Neuron 10 , 243-254. doi: 10.1016/0896-6273(93)90315-i

Mattson, M. P., Rydel, R. E., Lieberburg, I., and Smith-Swintosky, V. L. (1993b). Altered calcium signaling and neuronal injury: stroke and Alzheimer's disease as examples. Ann. N Y Acad. Sci. 679, 1-21. doi: 10.1111/j.1749-6632.1993. tb18285.x

Mattson, M. P., LaFerla, F. M., Chan, S. L., Leissring, M. A., Shepel, N., and Geiger, J. D. (2000). Calcium signaling in the ER: its role in neuronal plasticity and neurodegenerative disorders. Trends Neurosci. 23, 222-229. doi: 10.1016/s0166-2236(00)01548-4

Mayeux, R., Ottman, R., Tang, M., Noboa-Bauza, L., Marder, K., Gurland, B., et al. (1993). Genetic susceptibility and head injury as risk factors for Alzheimer's disease among community-dwelling elderly persons and their first-degree relatives. Ann. Neurol. 33, 494-501. doi: 10.1002/ana.4103 30513

McAllister, T. W. (2011). Neurobiological consequences of traumatic brain injury. Dialogues Clin. Neurosci. 13, 287-300.

Meziane, H., Dodart, J. C., Mathis, C., Little, S., Clemens, J., Paul, S. M., et al. (1998). Memory-enhancing effects of secreted forms of the $\beta$-amyloid precursor protein in normal and amnestic mice. Proc. Natl. Acad. Sci. U S A 95, 12683-12688. doi: 10.1073/pnas.95.21.12683

Mielke, M. M., Savica, R., Wiste, H. J., Weigand, S. D., Vemuri, P., Knopman, D. S., et al. (2014). Head trauma and in vivo measures of amyloid and neurodegeneration in a population-based study. Neurology 82, 70-76. doi: 10.1212/01.wnl.0000438229.56094.54

Milosch, N., Tanriöver, G., Kundu, A., Rami, A., Francois, J., Baumkötter, F., et al. (2014). Holo-APP and G-protein-mediated signaling are required for sAPPa-induced activation of the Akt survival pathway. Cell Death Dis. 5:e1391. doi: $10.1038 /$ cddis. 2014.352

Moretti, L., Cristofori, I., Weaver, S. M., Chau, A., Portelli, J. N., and Grafman, J. (2012). Cognitive decline in older adults with a history of traumatic brain injury. Lancet Neurol. 11, 1103-1112. doi: 10.1016/s1474-4422(12) 70226-0

Mortimer, J., van Duijn, C., Chandra, V., Fratiglioni, L., Graves, A., Heyman, A., et al. (1991). Head trauma as a risk factor for Alzheimer's disease: a collaborative re-analysis of case-control studies. EURODEM risk factors research group. Int. J. Epidemiol. 20, 28-35. doi: 10.1093/ije/20. supplement_2.s28

Mukda, S., Panmanee, J., Boontem, P., and Govitrapong, P. (2016). Melatonin administration reverses the alteration of amyloid precursor protein-cleaving 
secretases expression in aged mouse hippocampus. Neurosci. Lett. 621, 39-46. doi: 10.1016/j.neulet.2016.04.013

Müller, T., Meyer, H. E., Egensperger, R., and Marcus, K. (2008). The amyloid precursor protein intracellular domain (AICD) as modulator of gene expression, apoptosis and cytoskeletal dynamics-Relevance for Alzheimer's disease. Prog. Neurobiol. 85, 393-406. doi: 10.1016/j.pneurobio.2008. 05.002

Müller, U. C., and Zheng, H. (2012). Physiological functions of APP family proteins. Cold Spring Harb. Perspect. Med. 2:a006288. doi: 10.1101/cshperspect. a006288

Multhaup, G., Huber, O., Buée, L., and Galas, M. C. (2015). Amyloid precursor protein (APP) metabolites APP intracellular fragment (AICD), A $\beta 42$ and tau in nuclear roles. J. Biol. Chem. 290, 23515-23522. doi: 10.1074/jbc.r115. 677211

Murakami, N., Yamaki, T., Iwamoto, Y., Sakakibara, T., Kobori, N., Fushiki, S., et al. (1998). Experimental brain injury induces expression of amyloid precursor protein, which may be related to neuronal loss in the hippocampus. J. Neurotrauma 15, 993-1003. doi: 10.1089/neu.1998.15.993

Nagase, H., and Nakayama, K. (2014). The intracellular domain of amyloid precursor protein is a potential therapeutic target in Alzheimer's disease. Curr. Drug Discov. Technol. 11, 243-258. doi: 10.2174/15701638116661411211 01358

Nakayama, K., Ohkawara, T., Hiratochi, M., Koh, C.-S., and Nagase, H. (2008). The intracellular domain of amyloid precursor protein induces neuronspecific apoptosis. Neurosci. Lett. 444, 127-131. doi: 10.1016/j.neulet.2008. 08.034

Nikolaev, A., McLaughlin, T., O'Leary, D., and Tessier-Lavigne, M. (2009). N-APP binds DR6 to cause axon pruning and neuron death via distinct caspases. Nature 457, 981-989. doi: 10.1038/nature07767

Van Nostrand, W. E. (2016). The influence of the amyloid B-protein and its precursor in modulating cerebral hemostasis. Biochim. Biophys. Acta 1862, 1018-1026. doi: 10.1016/j.bbadis.2015.10.020

Obregon, D., Hou, H., Giunta, B., Tian, J., Darlington, D., Shahaduzzaman, M., et al. (2012). sAPP- $\alpha$ modulates $\beta$-secretase activity and amyloid- $\beta$ generation. Nat. Commun. 3:777. doi: 10.1038/ncomms1781

O'Collins, V. E., Macleod, M. R., Donnan, G. A., Horky, L. L., van der Worp, B. H., and Howells, D. W. (2006). 1,026 experimental treatments in acute stroke. Ann. Neurol. 59, 467-477. doi: 10.1002/ana.20741

Orehek, A. J. (2012). The micron stroke hypothesis of Alzheimer's disease and dementia. Med. Hypotheses 78, 562-570. doi: 10.1016/j.mehy.2012.01.020

Orrenius, S., Zhivotovsky, B., and Nicotera, P. (2003). Regulation of cell death: the calcium-apoptosis link. Nat. Rev. Mol. Cell Biol. 4, 552-565. doi: $10.1038 / \mathrm{nrm} 1150$

Otsuka, N., Tomonaga, M., and Ikeda, K. (1991). Rapid appearance of $\beta$-amyloid precursor protein immunoreactivity in damaged axons and reactive glial cells in rat brain following needle stab injury. Brain Res. 568, 335-338. doi: 10.1016/0006-8993(91)91422-W

Ozaki, T., Li, Y., Kikuchi, H., Tomita, T., Iwatsubo, T., and Nakagawara, A. (2006). The intracellular domain of the amyloid precursor protein (AICD) enhances the p53-mediated apoptosis. Biochem. Biophys. Res. Commun. 351, 57-63. doi: 10.1016/j.bbrc.2006.09.162

Palop, J. J., and Mucke, L. (2010). Amyloid- $\beta$ induced neuronal dysfunction in Alzheimer's disease: from synapses toward neural networks. Nat. Neurosci. 13, 812-818. doi: 10.1038/nn.2583

Pardossi-Piquard, R., and Checler, F. (2012). The physiology of the $\beta$-amyloid precursor protein intracellular domain AICD. J. Neurochem. 120, 109-124. doi: 10.1111/j.1471-4159.2011.07475.x

Peers, C., Dallas, M. L., Boycott, H. E., Scragg, J. L., Pearson, H. A., and Boyle, J. P. (2009). Hypoxia and neurodegeneration. Ann. N Y Acad. Sci. 1177, 169-177. doi: 10.1111/j.1749-6632.2009.05026.x

Perez, R. G., Zheng, H., Van der Ploeg, L. H., and Koo, E. H. (1997). The beta-amyloid precursor protein of Alzheimer's disease enhances neuron viability and modulates neuronal polarity. J. Neurosci. 17, 9407-9414.

Pierce, J. E., Trojanowski, J. Q., Graham, D. I., Smith, D. H., and McIntosh, T. K. (1996). Immunohistochemical characterization of alterations in the distribution of amyloid precursor proteins and beta-amyloid peptide after experimental brain injury in the rat. J. Neurosci. 16, 1083-1090.
Pimentel-Coelho, P. M., Michaud, J. P., and Rivest, S. (2013). Effects of mild chronic cerebral hypoperfusion and early amyloid pathology on spatial learning and the cellular innate immune response in mice. Neurobiol. Aging 34, 679-693. doi: 10.1016/j.neurobiolaging.2012.06.025

Plummer, S., Van den Heuvel, C., Thornton, E., Corrigan, F., and Cappai, R. (2016). The neuroprotective properties of the amyloid precursor protein following traumatic brain injury. Aging Dis. 7, 163-179. doi: 10.14336/AD. 2015.0907

Pluta, R., Jabłoński, M., and Czuczwar, S. J. (2012). Postischemic dementia with Alzheimer phenotype: selectively vulnerable versus resistant areas of the brain and neurodegeneration versus $\beta$-amyloid peptide. Folia Neuropathol. 50, 101-109.

Pluta, R., Jabłoński, M., Ułamek-Kozioł, M., Kocki, J., Brzozowska, J., Januszewski, S., et al. (2013). Sporadic Alzheimer's disease begins as episodes of brain ischemia and ischemically dysregulated Alzheimer's disease genes. Mol. Neurobiol. 48, 500-515. doi: 10.1007/s12035-013-8439-1

Pluta, R., Ułamek, M., and Jabłoński, M. (2009). Alzheimer's mechanisms in ischemic brain degeneration. Anat. Rec. (Hoboken) 292, 1863-1881. doi: $10.1002 / \mathrm{ar} .21018$

Postina, R. (2012). Activation of $\alpha$-secretase cleavage. J. Neurochem. 120, 46-54. doi: 10.1111/j.1471-4159.2011.07459.x

Pottier, C., Wallon, D., Lecrux, A. R., Maltete, D., Bombois, S., Jurici, S., et al. (2012). Amyloid- $\beta$ protein precursor gene expression in Alzheimer's disease and other conditions. J. Alzheimers Dis. 28, 561-566. doi: 10.3233/JAD-2011111148

Priller, C., Bauer, T., Mitteregger, G., Krebs, B., Kretzschmar, H. A., and Herms, J. (2006). Synapse formation and function is modulated by the amyloid precursor protein. J. Neurosci. 26, 7212-7221. doi: 10.1523/JNEUROSCI.145006.2006

Prince, M., Wimo, A., Guerchet, M., Gemma-Claire, A., Wu, Y.-T., and Prina, M. (2015). World Alzheimer Report 2015: The Global Impact of Dementia-An Analysis of Prevalence, Incidence, Cost and Trends. London: Alzheimer's Disease International.

Puzzo, D., Privitera, L., Fa', M., Staniszewski, A., Hashimoto, G., Aziz, F., et al. (2011). Endogenous amyloid- $\beta$ is necessary for hippocampal synaptic plasticity and memory. Ann. Neurol. 69, 819-830. doi: 10.1002/ana.22313

Reiman, E. M. (2016). Alzheimer's disease: attack on amyloid- $\beta$ protein. Nature 537, 36-37. doi: 10.1038/537036a

Ring, S., Weyer, S. W., Kilian, S. B., Waldron, E., Pietrzik, C. U., Filippov, M. A., et al. (2007). The secreted $\beta$-amyloid precursor protein ectodomain APPs $\alpha$ is sufficient to rescue the anatomical, behavioral and electrophysiological abnormalities of APP-deficient mice. J. Neurosci. 27, 7817-7826. doi: 10.1523/JNEUROSCI.1026-07.2007

Roberts, G. W., Gentleman, S. M., Lynch, A., Murray, L., Landon, M., and Graham, D. I. (1994). Beta amyloid protein deposition in the brain after severe head injury: implications for the pathogenesis of Alzheimer's disease. J. Neurol. Neurosurg. Psychiatry 57, 419-425. doi: 10.1136/jnnp.57. 4.419

Rönnbäck, A., Pavlov, P. F., Mansory, M., Gonze, P., Marlière, N., Winblad, B., et al. (2016). Mitochondrial dysfunction in a transgenic mouse model expressing human amyloid precursor protein (APP) with the Arctic mutation. J. Neurochem. 136, 497-502. doi: 10.1111/jnc.13410

Russo, C., Venezia, V., Repetto, E., Nizzari, M., Violani, E., Carlo, P., et al. (2005). The amyloid precursor protein and its network of interacting proteins: physiological and pathological implications. Brain Res. Rev. 48, 257-264. doi: 10.1016/j.brainresrev.2004.12.016

Ryan, M. M., Morris, G. P., Mockett, B. G., Bourne, K., Abraham, W. C., Tate, W. P., et al. (2013). Time-dependent changes in gene expression induced by secreted amyloid precursor protein-alpha in the rat hippocampus. $B M C$ Genomics 14:376. doi: 10.1186/1471-2164-14-376

Sahathevan, R., Linden, T., Villemagne, V. L., Churilov, L., Ly, J. V., Rowe, C., et al. (2016). Positron emission tomographic imaging in stroke: cross-sectional and follow-up assessment of amyloid in ischemic stroke. Stroke 47, 113-119. doi: 10.1161/STROKEAHA.115.010528

Santos, S. F., Pierrot, N., Morel, N., Gailly, P., Sindic, C., and Octave, J. N. (2009). Expression of human amyloid precursor protein in rat cortical neurons inhibits calcium oscillations. J. Neurosci. 29, 4708-4718. doi: 10.1523/JNEUROSCI. 4917-08.2009 
Sastre, M., Walter, J., and Gentleman, S. M. (2008). Interactions between APP secretases and inflammatory mediators. J. Neuroinflammation 5:25. doi: 10.1186/1742-2094-5-25

Schettini, G., Govoni, S., Racchi, M., and Rodriguez, G. (2010). Phosphorylation of APP-CTF-AICD domains and interaction with adaptor proteins: signal transduction and/or transcriptional role-Relevance for Alzheimer pathology. J. Neurochem. 115, 1299-1308. doi: 10.1111/j.1471-4159.2010. 07044.x

Schofield, P. W., Tang, M., Marder, K., Bell, K., Dooneief, G., Chun, M., et al. (1997). Alzheimer's disease after remote head injury: an incidence study. J. Neurol. Neurosurg. Psychiatry 62, 119-124. doi: 10.1136/jnnp.62.2.119

Schreiber, S., Drukarch, B., Garz, C., Niklass, S., Stanaszek, L., Kropf, S., et al. (2014). Interplay between age, cerebral small vessel disease, parenchymal amyloid- $\beta$ and tau pathology: longitudinal studies in hypertensive stroke-prone rats. J. Alzheimers Dis. 42, 205-215. doi: 10.3233/JAD-132618

Schrenk-Siemens, K., Perez-Alcala, S., Richter, J., Lacroix, E., Rahuel, J., Korte, M., et al. (2008). Embryonic stem cell-derived neurons as a cellular system to study gene function: lack of amyloid precursor proteins APP and APLP2 leads to defective synaptic transmission. Stem Cells 26, 2153-2163. doi: 10.1634/stemcells.2008-0010

Seabrook, G. R., Smith, D. W., Bowery, B. J., Easter, A., Reynolds, T., Fitzjohn, S. M., et al. (1999). Mechanisms contributing to the deficits in hippocampal synaptic plasticity in mice lacking amyloid precursor protein. Neuropharmacology 38, 349-359. doi: 10.1016/s0028-3908(98) 00204-4

Selkoe, D. J. (2002). Alzheimer's disease is a synaptic failure. Science 298, 789-791. doi: 10.1126/science.1074069

Selkoe, D. J. (2011). Resolving controversies on the path to Alzheimer's therapeutics. Nat. Med. 17, 1060-1065. doi: 10.1038/nm.2460

Selnes, P., Blennow, K., Zetterberg, H., Grambaite, R., Rosengren, L., Johnsen, L., et al. (2010). Effects of cerebrovascular disease on amyloid precursor protein metabolites in cerebrospinal fluid. Cerebrospinal Fluid Res. 7:10. doi: 10.1186/1743-8454-7-10

Siopi, E., Llufriu-Dabén, G., Cho, A. H., Vidal-Lletjós, S., Plotkine, M., Marchand-Leroux, C., et al. (2013). Etazolate, an $\alpha$-secretase activator, reduces neuroinflammation and offers persistent neuroprotection following traumatic brain injury in mice. Neuropharmacology 67, 183-192. doi: 10.1016/j. neuropharm.2012.11.009

Sivanandam, T. M., and Thakur, M. K. (2012). Traumatic brain injury: a risk factor for Alzheimer's disease. Neurosci. Biobehav. Rev. 36, 1376-1381. doi: 10.1016/j. neubiorev.2012.02.013

Smith-Swintosky, V. L., Pettigrew, L. C., Craddock, S. D., Culwell, A. R., Rydel, R. E., and Mattson, M. P. (1994). Secreted forms of $\beta$-amyloid precursor protein protect against ischemic brain injury. J. Neurochem. 63, 781-784. doi: 10.1046/j.1471-4159.1994.63020781.x

Stein, T. D., Anders, N. J., DeCarli, C., Chan, S. L., Mattson, M. P., and Johnson, J. A. (2004). Neutralization of transthyretin reverses the neuroprotective effects of secreted amyloid precursor protein (APP) in APPSW mice resulting in tau phosphorylation and loss of hippocampal neurons: support for the amyloid hypothesis. J. Neurosci. 24, 7707-7717. doi: 10.1523/JNEUROSCI.2211-04.2004

Steinbach, J. P., Müller, U., Leist, M., Li, Z. W., Nicotera, P., and Aguzzi, A. (1998). Hypersensitivity to seizures in $\beta$-amyloid precursor protein deficient mice. Cell Death Differ. 5, 858-866. doi: 10.1038/sj.cdd.4400391

Stephenson, D. T., Rash, K., and Clemens, J. A. (1992). Amyloid precursor protein accumulates in regions of neurodegeneration following focal cerebral ischemia in the rat. Brain Res. 593, 128-135. doi: 10.1016/0006-8993(92) 91274-i

Sun, D. A., Deshpande, L. S., Sombati, S., Baranova, A., Wilson, M. S., Hamm, R. J., et al. (2008). Traumatic brain injury causes a long-lasting calcium $\left(\mathrm{Ca}^{2+}\right)$-plateau of elevated intracellular $\mathrm{Ca}$ levels and altered $\mathrm{Ca}^{2+}$ homeostatic mechanisms in hippocampal neurons surviving brain injury. Eur. J. Neurosci. 27, 1659-1672. doi: 10.1111/j.1460-9568.2008. 06156.x

Sun, X., He, G., Qing, H., Zhou, W., Dobie, F., Cai, F., et al. (2006). Hypoxia facilitates Alzheimer's disease pathogenesis by up-regulating BACE1 gene expression. Proc. Natl. Acad. Sci. U S A 103, 18727-18732. doi: 10.1073/pnas. 0606298103
Swerdlow, R. H., and Khan, S. M. (2004). A “mitochondrial cascade hypothesis" for sporadic Alzheimer's disease. Med. Hypotheses 63, 8-20. doi: 10.1016/j. mehy.2003.12.045

Tarasoff-Conway, J. M., Carare, R. O., Osorio, R. S., Glodzik, L., Fieremans, E., Axel, L., et al. (2015). Clearance systems in the brain-implications for Alzheimer disease. Nat. Rev. Neurol. 11, 457-470. doi: 10.1038/nrneurol. 2015.119

Taylor, C. J., Ireland, D. R., Ballagh, I., Bourne, K., Marechal, N. M., Turner, P. R., et al. (2008). Endogenous secreted amyloid precursor protein- $\alpha$ regulates hippocampal NMDA receptor function, long-term potentiation and spatial memory. Neurobiol. Dis. 31, 250-260. doi: 10.1016/j.nbd.2008.04.011

Thibault, O., Gant, J. C., and Landfield, P. W. (2007). Expansion of the calcium hypothesis of brain aging and Alzheimer's disease: minding the store. Aging Cell 6, 307-317. doi: 10.1111/j.1474-9726.2007.00295.x

Thiel, A., Cechetto, D. F., Heiss, W., Hachinski, V., and Whitehead, S. N. (2014). Amyloid burden, neuroinflammation and links to cognitive decline after ischemic stroke. Stroke 45, 2825-2829. doi: 10.1161/STROKEAHA.114. 004285

Thornton, E., Vink, R., Blumbergs, P. C., and Van Den Heuvel, C. (2006). Soluble amyloid precursor protein $\alpha$ reduces neuronal injury and improves functional outcome following diffuse traumatic brain injury in rats. Brain Res. 1094, 38-46. doi: 10.1016/j.brainres.2006.03.107

Tolppanen, A.-M., Lavikainen, P., Solomon, A., Kivipelto, M., Soininen, H., and Hartikainen, S. (2013). Incidence of stroke in people with Alzheimer disease: a national register-based approach. Neurology 80, 353-358. doi: 10.1212/wnl. 0b013e31827f08c5

de la Torre, J. C. (2002). Vascular basis of Alzheimer's pathogenesis. Ann. N Y Acad. Sci. 977, 196-215. doi: 10.1111/j.1749-6632.2002.tb04817.x

de la Torre, J. C. (2006). How do heart disease and stroke become risk factors for Alzheimer's disease? Neurol. Res. 28, 637-644. doi: 10.1179/016164106x 130362

Tosto, G., Bird, T., Bennett, D., Boeve, B., Brickman, A., Cruchaga, C., et al. (2016). The role of cardiovascular risk factors and stroke in familial alzheimer disease. JAMA Neurol. 73, 1231-1237. doi: 10.1001/jamaneurol. 2016.2539

Traylor, M., Adib-Samii, P., Harold, D., Alzheimer's Disease Neuroimaging Initiative, International Stroke Genetics Consortium (ISGC), UK Young Lacunar Stroke DNA resource, Dichgans, M., et al. (2016). Shared genetic contribution to ischemic stroke and Alzheimer's disease. Ann. Neurol. 79, 739-747. doi: 10.1002/ana.24621

Trotman, M., Vermehren, P., Gibson, C. L., and Fern, R. (2015). The dichotomy of memantine treatment for ischemic stroke: dose-dependent protective and detrimental effects. J. Cereb. Blood Flow Metab. 35, 230-239. doi: $10.1038 /$ jcbfm. 2014.188

Tsitsopoulos, P. P., and Marklund, N. (2013). Amyloid- $\beta$ peptides and tau protein as biomarkers in cerebrospinal and interstitial fluid following traumatic brain injury: a review of experimental and clinical studies. Front. Neurol. 4:79. doi: 10.3389/fneur.2013.00079

Umeda, T., Tomiyama, T., Sakama, N., Tanaka, S., Lambert, M. P., Klein, W. L., et al. (2011). Intraneuronal amyloid $B$ oligomers cause cell death via endoplasmic reticulum stress, endosomal/lysosomal leakage and mitochondrial dysfunction in vivo. J. Neurosci. Res. 89, 1031-1042. doi: 10.1002/jnr. 22640

Vassar, R., Kuhn, P. H., Haass, C., Kennedy, M. E., Rajendran, L., Wong, P. C., et al. (2014). Function, therapeutic potential and cell biology of BACE proteases: current status and future prospects. J. Neurochem. 130, 4-28. doi: 10.1111/jnc. 12715

Venezia, V., Nizzari, M., Carlo, P., Corsaro, A., Florio, T., and Russo, C. (2007). Amyloid precursor protein and presenilin involvement in cell signaling. Neurodegener. Dis. 4, 101-111. doi: 10.1159/000101834

Wang, B., Wang, Z., Sun, L., Yang, L., Li, H., Cole, A. L., et al. (2014). The amyloid precursor protein controls adult hippocampal neurogenesis through GABAergic interneurons. J. Neurosci. 34, 13314-13325. doi: 10.1523/JNEUROSCI.2848-14.2014

Wang, P., Yang, G., Mosier, D. R., Chang, P., Zaidi, T., Gong, Y., et al. (2005). Defective neuromuscular synapses in mice lacking amyloid precursor protein (APP) and APP-like protein 2. J. Neurosci. 25, 1219-1225. doi: 10.1523/JNEUROSCI.4660-04.2005 
Webster, N. J., Ramsden, M., Boyle, J. P., Pearson, H. A., and Peers, C. (2006). Amyloid peptides mediate hypoxic increase of L-type $\mathrm{Ca}^{2+}$ channels in central neurones. Neurobiol. Aging 27, 439-445. doi: 10.1016/j.neurobiolaging.2005. 02.002

Weyer, S. W., Klevanski, M., Delekate, A., Voikar, V., Aydin, D., Hick, M., et al. (2011). APP and APLP2 are essential at PNS and CNS synapses for transmission, spatial learning and LTP. EMBO J. 30, 2266-2280. doi: 10.1038/emboj.2011.119

Wiesmann, M., Kiliaan, A. J., and Claassen, J. A. (2013). Vascular aspects of cognitive impairment and dementia. J. Cereb. Blood Flow Metab. 33, 1696-1706. doi: 10.1038/jcbfm.2013.159

Yang, X., Sheng, W., Ridgley, D. M., Haidekker, M. A., Sun, G. Y., and Lee, J. C. (2015). Astrocytes regulate $\alpha$-secretase-cleaved soluble amyloid precursor protein secretion in neuronal cells: involvement of group IIA secretory phospholipase A2. Neuroscience 300, 508-517. doi: 10.1016/j.neuroscience. 2015.05.052

Yang, S., Sun, R., Zhou, Z., Zhou, J., Liang, J., and Mu, H. (2014). Expression of amyloid- $\beta$ protein and amyloid- $\beta$ precursor protein after primary brain-stem injury in rats. Am. J. Forensic Med. Pathol. 35, 201-205. doi: 10.1097/PAF. 0000000000000103

Yang, L., Wang, Z., Wang, B., Justice, N. J., and Zheng, H. (2009). Amyloid precursor protein regulates Cav1.2 L-type calcium channel levels and function to influence GABAergic short-term plasticity. J. Neurosci. 29, 15660-15668. doi: 10.1523/JNEUROSCI.4104-09.2009

Yao, H., and Haddad, G. G. (2004). Calcium and pH homeostasis in neurons during hypoxia and ischemia. Cell Calcium 36, 247-255. doi: 10.1016/j.ceca. 2004.02.013

Zetterberg, H., Mörtberg, E., Song, L., Chang, L., Provuncher, G. K., Patel, P. P., et al. (2011). Hypoxia due to cardiac arrest induces a time-dependent increase in serum amyloid $\beta$ levels in humans. PLoS One 6:e28263. doi: 10.1371/journal. pone. 0028263

Zhang, X., Herrmann, U., Weyer, S. W., Both, M., Müller, U. C., Korte, M., et al. (2013). Hippocampal network oscillations in APP/APLP2-deficient mice. PLoS One 8:e61198. doi: 10.1371/journal.pone.0061198
Zhang, H., Wu, L., Pchitskaya, E., Zakharova, O., Saito, T., Saido, T., et al. (2015). Neuronal store-operated calcium entry and mushroom spine loss in amyloid precursor protein knock-in mouse model of Alzheimer's disease. J. Neurosci. 35, 13275-13286. doi: 10.1523/JNEUROSCI.103415.2015

Zhao, J., O'Connor, T., and Vassar, R. (2011). The contribution of activated astrocytes to $A \beta$ production: implications for Alzheimer's disease pathogenesis. J. Neuroinflammation 8:150. doi: 10.1186/1742-2094-8-150

Zhao, Z., Nelson, A. R., Betsholtz, C., and Zlokovic, B. V. (2015). Establishment and dysfunction of the blood-brain barrier. Cell 163, 1064-1078. doi: 10.1016/j. cell.2015.10.067

Zhou, Z., Chan, C. H., Ma, Q., Xu, X., Xiao, Z., and Tan, E.-K. (2011). The roles of amyloid precursor protein (APP) in neurogenesis: implications to pathogenesis and therapy of Alzheimer disease. Cell Adh. Migr. 5, 280-292. doi: 10.4161/cam. 5.4.16986

Zhou, J., Yu, J., Wang, H., Meng, X., Tan, C., Wang, J., et al. (2015). Association between stroke and Alzheimer's disease: systematic review and meta-analysis. J. Alzheimers Dis. 43, 479-489. doi: 10.3233/JAD-140666

Zuccotti, A., Clementi, S., Reinbothe, T., Torrente, A., Vandael, D. H., and Pirone, A. (2011). Structural and functional differences between L-type calcium channels: crucial issues for future selective targeting. Trends Pharmacol. Sci. 32, 366-375. doi: 10.1016/j.tips.2011.02.012

Conflict of Interest Statement: The authors declare that the research was conducted in the absence of any commercial or financial relationships that could be construed as a potential conflict of interest.

Copyright $\odot 2017$ Hefter and Draguhn. This is an open-access article distributed under the terms of the Creative Commons Attribution License (CC BY). The use, distribution and reproduction in other forums is permitted, provided the original author(s) or licensor are credited and that the original publication in this journal is cited, in accordance with accepted academic practice. No use, distribution or reproduction is permitted which does not comply with these terms. 